ARTIGO

\title{
MAPEAMENTO SISTEMÁTICO DE TECNOLOGIAS SOCIAIS NO BRASIL: SUBSÍDIO PARA FORMAÇÃO DOCENTE NO INSTITUTO FEDERAL DE SERGIPE
}

\author{
GRAZIELLA ROLLEMBERG \\ ORCID: https://orcid.org/0000-0002-6897-7956 \\ MÁRIO ANDRÉ DE FREITAS FARIAS ${ }^{2}$ \\ ORCID: https://orcid.org/0000-0002-4111-1298
}

\begin{abstract}
RESUMO: O debate sobre as Tecnologias Sociais tem chegado a vários setores da sociedade, incluindo as instituições de ensino e pesquisa. Entretanto, ainda são poucos os projetos desse tipo produzidos nesses contextos e há carência na formação voltada para o desenvolvimento prático desse tipo de intervenção em comunidades brasileiras, o que dificulta sua viabilização, sobretudo em contextos educacionais, nos quais é preciso planejar e avaliar as ações educativas.

Neste artigo, as TS são analisadas sob a perspectiva de sua aplicação à Educação Profissional e Tecnológica, especificamente nos Institutos Federais. São apresentados os resultados de um Estudo de Mapeamento Sistemático que selecionou estudos primários indicativos de aspectos metodológicos de desenvolvimento de projetos concretos de TS implementados em comunidades brasileiras. Ao final do mapeamento, 186 artigos, i.e. apenas 5,9\% da amostra analisada, evidenciaram a metodologia aplicada ao desenvolvimento da TS. A partir da discussão dos resultados do mapeamento, foi conduzida uma Análise Temática para analisar qualitativamente padrões significativos do conjunto de dados que revelassem métodos e processos de produção de TS, no sentido de sistematizar um produto educacional de formação docente. O produto propôs trilhas colaborativas de desenvolvimento de TS adequadas às especificidades locais com a meta de elaborar um projeto em TS aplicável a seus Campi de atuação no Instituto Federal de Sergipe (IFS). Como forma de aplicação e avaliação do produto educacional, foi desenvolvido um Estudo de Caso com docentes e técnicos do IFS - Campus Lagarto que resultou em bons prognósticos de aplicação mais ampla.
\end{abstract}

Palavras-chave: Educação Profissional e Tecnológica, Tecnologias Sociais, Produto educacional, Formação docente.

\section{SYSTEMATIC MAPPING OF SOCIAL TECHNOLOGIES IN BRAZIL: SUBSIDY FOR TEACHER EDUCATION AT THE INSTITUTO FEDERAL DE SERGIPE}

\footnotetext{
${ }^{1}$ Professor do Programa de Mestrado Profissional em Educação Profissional e Tecnológica do Instituto Federal de Sergipe. Lagarto, SE, Brasil. <mario.andre@ifs.edu.br>

${ }^{2}$ Mestre em Educação Profissional e Tecnológica pelo Instituto Federal de Sergipe; Pesquisadora Especialista Visitante B no CNPq. Aracaju, SE, Brasil. <graziroll@gmail.com> 


\begin{abstract}
The debate on Social Technologies (ST) has reached various sectors of society, including educational and research institutions. However, there are still few projects of this type produced in these contexts and training aimed at the practical development of this type of intervention in Brazilian communities is still lacking, which makes feasibility, especially in educational contexts, in which it is necessary to plan and evaluate actions educational.

In this article, the ST are analyzed from the perspective of their application to Professional and Technological Education, specifically at Federal Institutes. The results of a Systematic Mapping Study are presented, which selected primary studies indicative of methodological aspects of the development of concrete ST projects implemented in Brazilian communities. At the end of the mapping, 186 articles (only $5.9 \%$ of the sample analyzed) showed the methodology applied to the development of ST. From the discussion of the results of the mapping, a Thematic Analysis was conducted to qualitatively analyze significant patterns of the data set that revealed methods and processes of ST production to systematize an educational product of teacher training. The product proposed collaborative trails for the development of ST appropriate to local specificities with the goal of developing a project in ST applicable to their fields of activity at the Instituto Federal de Sergipe (IFS). As a way of applying and evaluating the educational product, a Case Study was developed with teachers and technicians from IFS - Campus Lagarto, which resulted in good prognoses of wider application.
\end{abstract}

Keywords: Professional and Technological Education, Social Technologies, Educational product, Teacher training.

\title{
MAPEO SISTEMÁTICO DE TECNOLOGÍAS SOCIALES EN BRASIL: FUNDACIÓN PARA LA FORMACIÓN DE PROFESORES EN EL INSTITUTO FEDERAL DE SERGIPE
}

RESÚMEN: El debate sobre las tecnologías sociales ha llegado a diversos sectores de la sociedad, incluidas las instituciones educativas y de investigación. Sin embargo, todavía son pocos los proyectos de este tipo producidos en estos contextos y hay una falta de formación dirigida al desarrollo práctico de este tipo de intervención en las comunidades brasileñas, lo que hace que su viabilidad, especialmente en contextos educativos, en los que es necesario planificar y evaluar acciones educativo.

En este artículo, los TS son analizados desde la perspectiva de su aplicación a la Educación Profesional y Tecnológica, específicamente en los Institutos Federales. Se presentan los resultados de un Estudio de Mapeo Sistemático, que seleccionó estudios primarios indicativos de aspectos metodológicos del desarrollo de proyectos concretos de TS implementados en comunidades brasileñas. Al final del mapeo, 186 artículos, es decir, solo el 5,9\% de la muestra analizada, mostraron la metodología aplicada al desarrollo de TS. A partir de la discusión de los resultados del mapeo, se realizó un Análisis Temático para analizar cualitativamente patrones significativos del conjunto de datos que revelaron métodos y procesos de producción de TS, con el fin de sistematizar un producto educativo de la formación docente. El producto propuso senderos colaborativos para el desarrollo de TS adecuados a las especificidades locales con el objetivo de desarrollar un proyecto en TS aplicable a sus campos de actividad en el Instituto Federal de Sergipe (IFS). Como forma de aplicar y evaluar el producto educativo, se desarrolló un Caso de Estudio con profesores y técnicos de IFS - Campus Lagarto, que resultó en buenos pronósticos de aplicación más amplia.

Palabras clave: Educación profesional y tecnológica, Tecnologías Sociales, Producto educativo, Formación del profesorado. 


\section{INTRODUÇÃO}

Ao revisitarmos o contexto de disputa entre projetos de sociedade, característico do período de redemocratização do Brasil, no qual se buscava, sob o prisma da educação nacional, a construção de uma via mais progressista, comprometida com a classe trabalhadora, podemos identificar entre as concepções mais debatidas a defesa de um ensino médio unitário, com o trabalho como princípio educativo (SAVIANI, 1989), consubstanciado na proposta de ensino médio integrado (RAMOS, 2008, p. 2).

Tal proposta opõe-se à tradicional visão dual de ensino que reproduz as desigualdades e destina aos jovens das classes populares uma educação profissional funcional às exigências produtivas (CIAVATTA; RAMOS, 2011, p. 28), e aponta para um ensino médio técnico que incorpore ciência, trabalho, tecnologia e cultura como eixos indissociáveis (FRIGOTTO; CIAVATTA; RAMOS, 2005, p. 43-45), superando a fragmentação curricular e promovendo uma formação integrada sob o ponto de vista dos conhecimentos e integradora sob o ponto de vista humano.

Para Ciavatta (2008, p. 3), os termos "formação integrada", "formação politécnica" e, mais recentemente, "educação tecnológica", todos associados à proposta de ensino médio integrado, buscam responder às necessidades de um mundo do trabalho perpassado pela ciência e pela tecnologia, as quais, se por uma lado, são forças produtivas e geradoras de valores e de riqueza, por outro, mediante a sua apropriação privada, são origem da exclusão, da precariedade, do subemprego, do desemprego, da perda dos vínculos comunitários e da própria identidade.

O objetivo dessa proposta de educação é, portanto, garantir aos jovens uma formação completa para a leitura crítica do mundo, para a compreensão das relações sociais subjacentes a todos os fenômenos e para a intervenção efetiva na realidade social (CIAVATTA; FRIGOTTO; RAMOS, 2005, p. 85), como esclarece Simões (2007, p. 84):

O ensino técnico articulado ao ensino médio, preferencialmente integrado, representa para a juventude uma possibilidade que não só colabora na [...] sobrevivência econômica e inserção social, como também uma proposta educacional, que na integração de campos do saber, tornase fundamental para os jovens na perspectiva do desenvolvimento pessoal e da transformação da realidade social em que estão inseridos.

A proposição está ancorada, de modo mais amplo, a uma perspectiva dos estudos sobre Ciência, Tecnologia e Sociedade (CTS) que defende a integração do processo tecnocientífico ao contexto social e a participação democrática da população, tanto no desenvolvimento de tal processo quanto na fruição de seus benefícios, buscando o desenvolvimento local sob uma nova racionalidade ligada à inclusão social e econômica, à sustentabilidade e às relações solidárias.

Podemos reconhecer, sob vários aspectos, a tentativa de aplicação concreta dessas ideias ao processo de criação e implantação das Rede Federal de Educação Profissional e Tecnológica (RFEPCT) e a criação dos Institutos Federais de Educação, Ciência e Tecnologia (IFs) no Brasil, por meio da Lei n 11.892/2008. No texto dessa Lei está presente a defesa de uma educação voltada para: a apreensão de conceitos como sistema de relações de uma totalidade concreta; a promoção de uma visão não determinista da ciência e da tecnologia; uma concepção de desenvolvimento socioeconômico orientado para a construção de uma sociedade mais justa e igualitária; uma formação para a intervenção ativa na realidade social vivida pelas comunidades do entorno dos IFs.

Os IFs, segundo Silva et al (2009), foram criados com o intuito de promover e incentivar a justiça social, o desenvolvimento sustentável, a inclusão social e a criação de soluções técnicas e novas tecnologias, atendendo à EPT e dando suporte aos arranjos produtivos locais. Em consonância com tal entendimento, a Lei $n^{\circ} 11.892 / 2008$, que criou os IFs, preconiza em seu Artigo $6^{\circ}$, entre as finalidades 
dessas instituições, a oferta de EPT como processo educativo e investigativo de geração e adaptação de soluções técnicas e tecnológicas às demandas sociais e peculiaridades regionais e a promoção da produção, desenvolvimento e transferência de Tecnologias Sociais (BRASIL, 2008).

I - Ofertar EPT, formando e qualificando cidadãos com vistas na atuação profissional nos diversos setores da economia, com ênfase no desenvolvimento socioeconômico local, regional e nacional;

II - Desenvolver a EPT como processo educativo e investigativo de geração e adaptação de soluções técnicas e tecnológicas às demandas sociais e peculiaridades regionais; [...]

IX - Promover a produção, o desenvolvimento e a transferência de tecnologias sociais, notadamente as voltadas à preservação do meio ambiente. [grifos nossos] (BRASIL, 2008).

Os estudos sobre Tecnologias Sociais são multidisciplinares e relativamente recentes; o conceito ainda é alvo de debates e tende a um caráter polissêmico, inspirado por diferentes perspectivas teórico-metodológicas, ainda que suas variações mantenham elementos essenciais em comum. Adotaremos aqui, como ponto de partida, o conceito de Rodrigues e Barbieri (2008) de TS como construção de soluções de modo coletivo pelos atores sociais que irão se beneficiar dessas soluções com apoio externo, se necessário - e atuar com autonomia para aplicá-las de modo sustentável, ou seja, não atuando apenas como usuários de soluções tecnológicas transferidas de outros lugares - transferência de tecnologia - ou produzidas exclusivamente por equipes de especialistas, mas agindo de modo a apropriar-se da tecnologia social sob a lógica do desenvolvimento da própria comunidade. (RODRIGUES; BARBIERI, 2008, p. 1075).

$\mathrm{Na}$ busca de caracterizar de modo objetivo as experiências práticas em TS, Maciel e Fernandes (2011) propõem elementos fundamentais que devem integrar os projetos de TS, os quais tomamos como parâmetros orientadores da pesquisa que originou este artigo: potencial de transformação social; participação direta da população; sentido de inclusão social; melhoria das condições de vida; sustentabilidade socioambiental e econômica; caráter de inovação; capacidade de atender necessidades sociais específicas; organização e sistematização da tecnologia; diálogo entre diferentes saberes (acadêmicos e populares); acessibilidade e apropriação das tecnologias pelas comunidades-alvo; difusão e ação educativa; construção da cidadania e de processos democráticos.

Sob perspectiva educativa, uma das ideias em debate, inspirada em Latour (1994), é a de TS como ferramenta de flexibilização da hierarquia entre os saberes sob um prisma dialético e inclusivo, de construção de aprendizagens e conhecimentos coletivos.

Para Dagnino (2014), as TS buscam a inclusão por meio da desconstrução da concepção de que os problemas sociais das comunidades devem ser definidos e solucionados segundo o modelo cognitivo de outros atores, e não a partir do modelo das próprias comunidades. Apontam, portanto, para uma práxis comunitária, com o suporte do diálogo entre os saberes técnico-científicos e os populares, e representando uma plataforma cognitiva para formas alternativas de desenvolvimento, mais democráticas e solidárias.

Sob o ponto de vista do currículo e dos processos educativos, as TS envolvem dinâmicas de educação não formal e dimensões da produção de conhecimentos relacionadas a diferentes tipos de saberes - teóricos, conceituais, científicos, técnicos, tecnológicos e práticos - e ainda saberes obtidos por meio da pesquisa participativa, pois é preciso descobrir e incorporar à TS a dimensão dos saberes populares, tradicionais, muitas vezes não codificados, ligados às práticas da comunidade, que também precisam ser mobilizados no sentido de produzir e planejar soluções inovativas para os problemas locais.

Kuenzer (1999) propõe, entre os eixos fundamentais para a formação de professores para a EPT, o eixo Práxico, que deve integrar conhecimento científico, conhecimento tácito e prática social. É 
sob o eixo práxico que consideramos que deva se articular a formação docente em TS, que, por sua vez, demanda uma fundamentação metodológica e orientações práticas para viabilizar o desenvolvimento de projetos de extensão em TS nos IFs, sob a perspectiva de uma EPT integrada e integradora de saberes.

No contexto específico dos IFs, o desenvolvimento de ações e projetos de extensão orientados para a produção de TS podem integrar de modo significativo e aplicado os conhecimentos, métodos e práticas ligadas tanto às disciplinas propedêuticas quanto às relacionadas às disciplinas técnicas e tecnológicas do ensino profissional, podendo também contribuir para a construção da autonomia dos estudantes, da compreensão crítica da totalidade em que estão inseridos, para a construção das capacidades de inovação, de resolução de problemas, de aplicação dos conhecimentos teóricos e práticos à realidade social da comunidade e ao mundo do trabalho.

A partir desse panorama, torna-se necessário refletir sobre os aspectos relacionadas à viabilidade prática de projetos de TS no contexto da EPT aplicada nos IFs e responder a algumas questões essenciais: Os IFs têm desenvolvido de modo sistemático projetos efetivamente de TS em seus campi? Como a formação docente para EPT pode dar conta da viabilização desse tipo de projeto? Existem orientações metodológicas sistematizadas sobre a produção de TS aplicáveis aos processos educativos e ao contexto dos IFs? De que forma é possível apoiar os docentes no desenvolvimento de TS nos IFs?

No cenário da EPT prevista para os IFs, apoiada sobre o tripé ensino/pesquisa/extensão, as ações extensionistas, como projetos de extensão tecnológica surgem como alternativa para o desenvolvimento de projetos de TS nos IFs, como defende Rios e Lima (2016, p. 95): "Essa ação possibilita tanto a criação como o reconhecimento, a divulgação e a valorização do trabalho coletivo consubstanciado em TS", pois auxilia a mediação da produção e aplicação de projetos que solucionem problemas da população local, o registro das etapas e seus resultados, e o compartilhamento dos conhecimentos produzidos.

É preciso destacar que a Extensão Tecnológica possui características distintas das extensões universitárias, apesar de com elas compartilhar o sentido de extensão como relação dialógica com a sociedade. A concepção de extensão nos IFs aparece no documento lançado em 2013 pelo Conselho Nacional das Instituições da Rede Federal de Educação Profissional, Científica e Tecnológica (CONIF):

\begin{abstract}
A extensão tecnológica da Rede Federal de EPCT tem como diferencial o atendimento aos segmentos sociais e ao mundo do trabalho com ênfase na inclusão social, emancipação do cidadão, favorecendo o desenvolvimento local e regional, a difusão do conhecimento científico e tecnológico, a produção da pesquisa aplicada e a sustentabilidade sócio econômica [...] as atividades de extensão devem estar articuladas com o ensino e a pesquisa suprindo as demandas da comunidade interna e externa, visando a compreensão e consolidação dos conhecimentos acadêmicos e populares, vinculados a uma ou mais dimensões da extensão (CONIF, 2013, p. 20).
\end{abstract}

No que concerne ao desenvolvimento de projetos de TS nos IFs, constatou-se, no âmbito dos levantamentos bibliográficos preliminares à pesquisa que deu origem a este trabalho, que, entre os projetos de extensão concluídos e em curso em IFs, são poucos os que se caracterizam efetivamente como TS (SOUZA; RUFINO, 2017, p. 106-112), pois parte significativa dos projetos nomeadamente voltados para TS, desenvolvidos em instituições federais, não correspondem aos critérios esperados para esse tipo de projeto, tais como o da apropriação e do aprendizado da TS por parte da comunidade e o do planejamento, da aplicação/sistematização e do registro de conhecimento produzido de forma organizada.

Sob o prisma da formação docente para o desenvolvimento de TS, é preciso considerar as especificidades e complexidades da EPT. Para Machado (2008, p. 18), 
[...] o perfil do docente da educação profissional precisa dar conta de três níveis de complexidade: a) desenvolver capacidades de usar, nível mais elementar relacionado à aplicação dos conhecimentos e ao emprego de habilidades instrumentais; b) desenvolver capacidades de produzir, que requer o uso de conhecimentos e habilidades necessários à concepção e execução de objetivos para os quais as soluções tecnológicas existem e devem ser adaptadas; e c) desenvolver capacidades de inovar, nível mais elevado de complexidade relacionado às exigências do processo de geração de novos conhecimentos e novas soluções tecnológicas (MACHADO, 2008a, p. 18).

A formação docente na EPT precisa, portanto, dar conta não só dos meios de desenvolver as capacidades de produzir e usar conhecimentos, mas também deve instrumentalizar os professores para desenvolver a capacidade de gerar novos conhecimentos e soluções técnicas.

É papel dos IFs contribuir para a formação de profissionais e produzir conhecimentos que sejam compatíveis com um projeto de sociedade mais justa e igualitária, promovendo o contato direto de alunos, professores e técnicos com as necessidades populares, através de uma prática dialógica de construção de conhecimento e de luta conjunta contra a exclusão: "a proposta de fortalecer o poder das camadas populares não está centrada na transmissão de conhecimento, mas na criação de um espaço onde o saber popular possa se expressar" (GARCIA, 1980, p. 92), o que se alinha à proposta de formação docente para o desenvolvimento de projetos de extensão em TS no contexto dos IFS. Entretanto, os levantamentos preliminares mostraram que não estão disponíveis para os docentes dos IFs materiais, produtos, cursos ou outros recursos de natureza metodológica ou didática voltados à produção ou adaptação de TS aplicáveis aos processos educativos da EPT.

A partir desse cenário, levantou-se a hipótese de que, entre os motivos da escassez de projetos de extensão em TS nos IFs, poderia se destacar a ausência de recursos de apoio metodológico sistematizado para a formação docente voltados ao desenvolvimento desse tipo de projeto. Para desenvolver soluções tecnológicas como as TS de modo sistemático, por meio de ações e projetos de extensão, é preciso criar itinerários e recursos educacionais de apoio à formação continuada dos docentes da EPT voltada para a mediação de práticas de intervenção social local

Delimitou-se então, como problema da pesquisa que originou este trabalho, a ausência de itinerários formativos e recursos de apoio à produção de TS no contexto dos IFs e, como proposta de solução, foi realizada a investigação de métodos e processos de desenvolvimento de TS aplicáveis à EPT, sua sistematização e transposição para um produto educacional de formação docente em TS. Esperamos com isso, subsidiar a elaboração e aplicação de projetos de extensão em TS voltados para o desenvolvimento local sustentável e a inclusão socioeconômica, a interação dialógica da comunidade acadêmica com a sociedade por meio da troca democrática de conhecimentos e saberes e a formação crítica e integral dos estudantes.

\section{REFERENCIAL TEÓRICO}

No contexto dos debates sobre o papel da Ciência e da Tecnologia na contemporaneidade e as suas relações com a sociedade, é preciso considerar o fenômeno da aceleração tecnológica e analisar as diferentes perspectivas teóricas elaboradas a partir da intensificação dos processos técnico-científicos e seus impactos nas dinâmicas sociais, culturais e econômicas, incluindo as transformações que vêm ocasionando na produção e divulgação do conhecimento e na natureza dos processos de ensino e aprendizagem, tanto nos âmbitos formais quanto nos informais da Educação.

Nesse cenário, se por um lado ainda é predominante a concepção tradicional de que o progresso crescente da ciência e da tecnologia é determinante para o desenvolvimento econômico e social, de outro há a perspectiva fundada nas indeterminações que rondam o futuro da sociedade, e que 
questiona o papel determinante e supostamente neutro da ciência e da tecnologia, apontando a necessidade de desenvolver tecnologias alternativas às tecnologias convencionais que se amparem em princípios mais democráticos e inclusivos (ROLLEMBERG, G.; FARIAS, M. F., 2018). No sentido de fundamentar tais questões, destacamos aqui trechos representativos da revisão da produção científica relativa às áreas que fundamentaram a pesquisa na qual o presente artigo se originou.

\section{Debates sobre Tecnologia, Inovação e Desenvolvimento: marco conceitual das TS}

O modelo da cadeia linear da inovação tecnológica convencional, inspiradao na interpretação liberal, que considera inovação e tecnologia como diretamente relacionadas ao mercado (SHUMPETER, 1985), supõe que a pesquisa científica é seguida pela tecnológica, que a pesquisa tecnológica, por sua vez, produz o desenvolvimento econômico, e este possibilita o desenvolvimento social (BAUNGARTEN, 2008, p. 5). Inovações, nessa acepção, seriam processos por meio dos quais novas ideias, objetos e práticas são criados, desenvolvidos ou reinventados (CROSSAN; APAYDIN, 2010, p. 1.155). Essa perspectiva, portanto, relaciona diretamente o avanço ou atraso das sociedades ao nível de sofisticação tecnológica que possuem, podendo ser classificada como uma concepção convencional de inovação tecnológica, ligada a um modelo liberal de interpretação da realidade e do próprio conceito de desenvolvimento.

Segundo Baumgarten (2005), tal modelo ancora-se na ideia de supremacia do homem sobre a natureza e considera a desigualdade econômica e social necessária, interpretando a inovação e a tecnologia como diretamente relacionadas ao mercado, às leis da oferta e da procura, e tomando-as como recursos de competitividade, apontando para os conceitos de tecnologias convencionais e de tecnociência. Ainda sobre o tema, Godinho (2003) defende que, mesmo que a concepção convencional de inovação esteja em debate, na prática continua presente, sendo muitas vezes detectada em programas e políticas públicas direcionadas para a ciência, tecnologia e inovação.

As tecnologias alternativas às tecnologias convencionais, por outro lado, estão ligadas a um outro modelo de inovação, a inovação social, conceituada por Mulgan et al (2006, p. 145-146) como relacionada a atividades e serviços inovadores que atendem às necessidades sociais, sendo desenvolvidos por organizações de cunho social, instituições de ensino e pesquisa e, por vezes, agentes públicos. As TS são, nesse quadro, exemplo de alternativa teórico-prática às tecnologias convencionais na busca de superar a perspectiva tecnocêntrica e difusionista e de construir uma perspectiva social para a ciência e a tecnologia sob uma racionalidade democrática e de integração entre saberes e práticas.

Outro modo de investigar as raízes das TS é o levantamento histórico das propostas de alternativa tecnológica, como as genericamente denominadas de Tecnologias Apropriadas (TA). A origem histórica desse tipo de alternativa tecnológica remonta ao processo de reabilitação das tecnologias tradicionais, praticadas em aldeias da Índia como estratégia de luta contra o domínio britânico no início do século XX, e que, mais tarde, nas décadas de 1960 e 1970, foram desenvolvidas em âmbito mundial.

Consideradas alternativas às tecnologias em uso nos países desenvolvidos, as TA foram transplantadas para vários países, principalmente por empresas multinacionais. Porém, tal processo não representou uma ruptura com o modelo de desenvolvimento capitalista vigente, pois, como afirma Pinto (2005), a transferência de tecnologia de regiões centrais para periféricas propiciam lucros para os que fazem a transferência e para os que serão seus proprietários, e não para a população que irá utilizá-la.

Após uma ampla análise do movimento da TA, Dagnino, Brandão e Novaes (2004) concluíram que as suas várias correntes revelam um produto, não um processo, já que a inovação não pode ser pensada como algo feito num lugar e aplicado em outro, e sim como desenvolvida no lugar onde a tecnologia será utilizada, pelos atores que irão utilizá-la. Para eles, a inovação social supõe um 
processo em que atores sociais interajam desde o início para conceber, em função de múltiplos critérios, - frequentemente tácitos e, às vezes, propositalmente não codificados (científicos, técnicos, financeiros, mercadológicos, culturais etc.) -, um conhecimento que eles mesmos irão utilizar localmente (DAGNINO, BRANDÃO; NOVAES, 2004). Essa ideia está na origem do que chamamos de TS.

\section{Perspectivas críticas sobre Ciência, Tecnologia e Sociedade: o papel das TS}

Segundo Kuhn (1989), o que as teses da neutralidade e da não-neutralidade da ciência e da tecnologia têm em comum é a impossibilidade de compreender a tecnologia como construção social; compreensão que fundamenta a concepção crítica mais recente da tecnologia. Sob essa perspectiva crítica ao paradigma tradicional de ciência e tecnologia, surge, sobretudo durante a década de 1970, na Europa e nos Estados Unidos, o movimento Ciência, Tecnologia e Sociedade (CTS).

Os pesquisadores envolvidos em tal movimento, segundo Auler (2011, p. 74-76), voltaramse para duas tendências, a europeia e a norte-americana; a primeira focada em questões acadêmicas envolvendo a investigação dos impactos do desenvolvimento científico e tecnológico na contemporaneidade, e a segunda em questões como as consequências sociais e ambientais dos produtos tecnológicos e os efeitos que o desenvolvimento científico e tecnológico surtia na sociedade e no meio ambiente, advogando pela participação democrática dos cidadãos nas decisões científicas e tecnológicas.

$\mathrm{Na}$ esteira da tendência norte-americana dos estudos CTS, surgiu a Teoria Crítica da Tecnologia, proposta por Feenberg (2004), que defendia que a tecnologia seria capaz de promover um desenvolvimento para atender às necessidades da sociedade; mas que, para isso, seria necessário um controle social que orientasse tal desenvolvimento, não mais sob a racionalidade técnica, mas sob uma racionalidade democrática, que considera a tecnologia a serviço da humanidade, e não o contrário.

No Brasil, autores como Sant'Anna (1978) já afirmavam décadas atrás que a sociedade brasileira nunca conseguiu superar a questão "Ciência e Tecnologia", ou mesmo apontar caminhos alternativos para o seu desenvolvimento sob a perspectiva das relações entre os sistemas produtivo e científico, em razão de o país ter renunciado ao desenvolvimento tecnológico autônomo em nome de uma supostamente mais rentável importação de tecnologia, ligada ao chamado modelo difusionista, que, para o autor, não estaria adequado às realidades locais.

Segundo Pinto (2005, p. 296-299), uma das consequências da hegemonia dessa concepção é que as regiões "não tecnológicas", menos desenvolvidas, correm o risco de planejar seu desenvolvimento tecnológico imitando as regiões mais desenvolvidas; esquecendo-se de suas condições objetivas. Para o autor, isso fica evidente nas transferências de tecnologia de "regiões centrais" para "regiões periféricas", em que muitos tomam a tecnologia das "regiões centrais" como as mais avançadas e, no processo de transplantação de tecnologia, privilegiam os lucros dos que fazem a transação e dos que serão proprietários dela, e não da população que irá acolhê-la.

A técnica, então, ganha mais centralidade do que o ser humano que irá recebê-la. Essa concepção, para o autor, deveria ser substituída por uma concepção social da tecnologia que considerasse o ser humano como centro dos processos e valorizasse as populações locais, que necessitam de soluções tecnológicas para transformar sua realidade e superar suas dificuldades econômicas, sociais, ambientais, educacionais etc. (PINTO, 2005, p. 296-299) Essa visão se aproxima da teoria de Feenberg, que toma a tecnologia como construção social, central no processo de democratização das relações de produção, sociais, e de construção e divulgação de conhecimentos.

A busca de superar a perspectiva convencional da tecnologia sob uma racionalidade democrática fez emergir um desafio: a possibilidade de pensar a tecnologia como uma dimensão da cultura, resgatando uma visão pedagógica e uma compreensão histórica que situa a tecnologia como uma 
atividade humana subordinada a outras dimensões humanas, e não como superior a elas, capaz de contribuir para a superação das desigualdades e para a inclusão social (DAGNINO, 2014), como é o caso das TS.

Para Dagnino e Bagattolli (2009, p. 8), é preciso difundir na comunidade de pesquisa que "a inclusão social somente será incentivada pela Política de Ciência e Tecnologia (PCT) quando for incluída na agenda decisória da política pública e, mais que isso, quando as TS integrarem as políticas públicas de PCT". Uma das vias apontadas pelos autores seria convencer a comunidade de pesquisa da conveniência de alterar suas agendas de docência, pesquisa e extensão, afastando-se dos cânones vigentes e reorientando o potencial de pesquisa e ensino em instituições públicas (DAGNINO; BAGATTOLLI, 2009, p. 3).

Costa (2013) ressalta, entretanto, que a TS, como instrumento de políticas públicas, carece de mediação entre as formas de funcionamento do Estado e as dinâmicas sociais das comunidades. Tal mediação pode ser desempenhada por atores ligados a organizações não governamentais e instituições de ensino e pesquisa, colaborando não só com os atores internos das comunidades-alvo, mas, também, com suas próprias instituições, pois, como destacam Klossowski, Freitas e Freitas (2016, p. 62), as ações de pesquisa e extensão são meios para operacionalizar o papel social das instituições públicas de ensino e aproximá-las da sociedade. Nesse sentido, as TS têm grande importância como instrumento de aplicação de ações extensionistas voltadas para demandas da sociedade sob uma perspectiva em que o saber científico possa se associar ao saber popular, em uma "relação de reciprocidade, mutuamente transformadora", (JEZINE, 2004, p. 3) e contribuir para a construção da autonomia e organização dos atores sociais das comunidades e para a transformação da realidade social.

\section{Tecnologias Sociais e Educação: conhecimento coletivo e intervenção social}

Ao tratar das TS sob o prisma educativo e considerando o que Gadotti (1988) nomeia como pedagogia da praxis, Soffner (2014, p. 311) sugere que as TS podem ser caracterizadas como projetos de pedagogia social, voltados para uma praxis sociocomunitária, pois produzem soluções que contribuem não só para a melhoria da qualidade de vida dos grupos sociais, como também para o desenvolvimento educativo integral das pessoas envolvidas na transformação social do ambiente ao qual se aplicam.

Para Maciel e Albagli (2004, p. 10), é essencial considerar que as aprendizagens no contexto da produção e aplicação de inovações sociais não se limitam ao simples acesso às informações, pois tal acesso não gera necessariamente conhecimento ou por si só altera estruturas cognitivas; elas referem-se a um processo bem mais amplo e complexo de aquisição e construção de diferentes tipos de conhecimentos, saberes, competências e habilidades e de sua mobilização em ação/inovação.

Referindo-se à produção de inovações sociais, as autoras (MACIEL; ALBAGLI, 2004) afirmam que o aprendizado deve ser pensado como relação social e levantam, ainda, outros autores, como Lundvall (2002) e Patrucco (2003), que destacam a importância do conhecimento tácito como fonte de inovação e o papel das interações locais na produção e na difusão de tal conhecimento e analisam os processos de geração e compartilhamento de conhecimentos - especialmente os tácitos - e sua influência sobre a capacidade inovativa local. Elas propõem que a produção, a socialização e o uso de conhecimentos e informações, assim como a conversão destes em inovações, são processos socioculturais, e apontam que:

[...] há lacunas no sentido de se definirem e desenvolverem metodologias e instrumentos de pesquisa que demonstrem empiricamente a relevância dos fluxos locais de conhecimento para a inovação e que evidenciem os fatores socioespaciais que interferem nesses fluxos (MACIEL; ALBAGLI, 2004, p. 9). 
Vários grupos de pesquisadores brasileiros da área de TS também consideram as dimensões do aprendizado coletivo fundamentais para esse tipo de projeto. O Instituto de Tecnologia Social (ITS, 2004) aponta a relevância da aprendizagem e da participação como processos simultâneos, sob compreensão sistêmica da realidade, respeitando as identidades locais. No mesmo caminho, Maciel e Fernandes (2011) propõem, como um dos elementos fundamentais para o desenvolvimento de TS, o diálogo entre diferentes saberes acadêmicos e populares; a acessibilidade e apropriação das TS pela comunidade e a difusão e ação educativa relativas a ela. Nota-se, em tais propostas, a valorização equânime dos tipos de saberes, indicando a colaboração orgânica entre pesquisadores e outros atores externos e os atores locais com seus saberes tradicionais, tácitos, não codificados.

Sob outro aspecto, Baumgarten (2005) enuncia que um elemento fundamental para a sustentabilidade econômica e social do país estaria na articulação entre produção de conhecimento - e seu locus privilegiado, as instituições de ensino e pesquisa - e a inovação social, e que as redes de pesquisadores e demais atores relacionados à produção e difusão do conhecimento podem ajudar a aprofundar as relações entre a coletividade científica e a sociedade brasileira, possibilitando o desenvolvimento de TS passíveis de integrarem-se à políticas públicas locais e regionais.

No contexto específico dos IFs, entretanto, segundo Pichetti (2018, p. 7), em dissertação sobre o papel dos Núcleos de Inovação Tecnológica (NIT) na promoção do uso das TS nos IFs, que considerou as cooperativas de autogestão como incluídas no rol das TS, 69,2\% dos IFs pesquisados não incentivou cooperativas entre 2013 e 2017. Em contrapartida, as iniciativas de transferência de tecnologia para a comunidade, no mesmo período, apareceram com ênfase muito maior (PICHETTI, 2018, p. 76$78)$.

O autor afirma que há pouco interesse de tais núcleos, presentes em todos os 38 IFs, em desenvolvimento e reaplicação de TS, mesmo considerando que tais funções estão entre as finalidades para as quais foram criados, e é clara a tendência de apoiar predominantemente a transferência de tecnologias convencionais, comprometendo o desenvolvimento regional sustentável, e conclui que:

a atuação dos NIT na educação profissional tecnológica poderia apontar para alternativas, como a priorização de atividades de extensão, que auxiliam de maneira mais incisiva à comunidade do entorno de suas instituições (PICHETT'TI, 2018, p. 86).

A partir desse cenário, a hipótese que consideramos ao longo da pesquisa é a de que o engajamento da própria comunidade docente dos IFs, apoiada por recursos de formação adequados e adaptáveis à sua ação docente e seu contexto educativo e sociocultural, possa gerar projetos de extensão que favoreçam o desenvolvimento de TS como forma de promover o desenvolvimento local e regional sustentável e, ainda, contribuir para a formação integral dos discentes.

\section{A Educação Profissional e Tecnológica sob perspectiva crítica}

O documento "Um novo modelo em Educação Profissional e Tecnológica: concepção e diretrizes", publicado em 2010 pela Secretaria de EPT, vinculada ao Ministério da Educação - MEC, apresenta uma concepção geral de EPT da Rede Federal:

[...] processos de formação com base nas premissas da integração e da articulação entre ciência, tecnologia, cultura e conhecimentos específicos e do desenvolvimento da capacidade de investigação científica como dimensões essenciais à manutenção da autonomia e dos saberes necessários ao permanente exercício da laboralidade, que se traduzem nas ações de ensino, pesquisa e extensão. Por outro lado, tendo em vista que é essencial à EPT contribuir para o progresso socioeconômico, as atuais políticas dialogam efetivamente com as políticas sociais e 
econômicas, dentre outras, com destaque para aquelas com enfoques locais e regionais. (MEC, 2010).

O documento destaca a nova institucionalidade trazida pelos IFs, não só no contexto da modalidade, mas também no cenário político, social e educacional da época de sua criação, no bojo de um novo projeto societário. O desafio posto é o de unificar a educação para o trabalho e a educação para a cidadania por meio da superação do paradigma da modernização competitiva, focando o desenvolvimento efetivo da sociedade. Para isso, é fundamental refletir sobre a construção de novos padrões educacionais, que incorporem o progresso técnico e tecnológico à educação de modo emancipador, e não reprodutor das desigualdades econômicas e sociais (FERRETI et al, 2003).

No contexto da EPT, esse novo paradigma passa pela reunião orgânica do ensino técnicoprofissional e do ensino propedêutico em uma totalidade curricular, o chamado ensino integrado; pela promoção de uma escola unitária que oferte educação de modo equânime para jovens de todas as classes sociais, de forma que todos tenham acesso aos conhecimentos, à cultura e às mediações necessárias para trabalhar e para produzir sua existência e a riqueza social (FRIGOT'TO; CIAVAT'TA; RAMOS, 2005); pela premissa de que o ser humano é um produtor de sua realidade, capaz de se apropriar dela e de transformá-la, o que torna o trabalho um princípio educativo; e pela noção de que formar profissionalmente não é apenas preparar para o exercício do trabalho, mas também para a compreensão das dinâmicas sócio-produtivas das sociedades modernas, habilitando as pessoas para o exercício autônomo e crítico de profissões (RAMOS, 2008).

De acordo com tal concepção, a formação docente nos IFs precisa voltar-se para a produção dialógica de conhecimentos, para a promoção do contato direto de alunos, professores e técnicos com as necessidades e os problemas das comunidades locais, das quais muitas vezes fazem parte, para uma luta coletiva contra a exclusão que incorpore os conhecimentos científicos e os saberes e práticas populares.

Segundo Moura (2014), a EPT é um espaço formativo no qual a luta contra-hegemônica é especialmente difícil, pois a formação de sujeitos capazes de analisar criticamente o modo de produção capitalista é contrária à própria lógica estruturante do sistema. O autor defende que é importante considerar as necessidades e expectativas tanto das redes de ensino quanto dos sujeitos da formação os docentes - que, por vezes, não têm formação inicial voltada para a docência e precisam de possibilidades para a formação didático-político-pedagógica em serviço.

Sob o aspecto tecnológico da formação docente na RFEPT, Machado (2008) aponta um descompasso entre a formação técnica e tecnológica para o mundo do trabalho e o entendimento conceitual e estratégico da técnica e da tecnologia na EPT, o que pode ser complementado por Freire e Batista (2017). Eles defendem que uma formação docente, nessa modalidade, precisaria contemplar um aprofundamento nos conceitos de tecnologia e em seus reflexos nas práticas socioculturais e políticas, o que pode ser viabilizado por meio de projetos de extensão, corroborando, assim, a nossa proposta de pesquisa e produção de produto educacional para a formação docente em TS no contexto da EPT desenvolvida nos IFs.

\section{METODOLOGIA}

A partir dos levantamentos bibliográficos, cujo resumo consta na seção de referências teóricas deste trabalho, identificou-se a escassez de informações objetivas sobre os aspectos metodológicos e práticos de desenvolvimento de projetos de TS no Brasil que pudessem subsidiar a sistematização de itinerários de formação continuada de docentes; o que, portanto, apontou para a 
necessidade de levantar revisão sistemática de literatura sobre TS que pudesse corroborar - ou não - tal hipótese.

No contexto de tais revisões, destaca-se o artigo de Gapinski e Freitas (2016), que analisa quantitativamente projetos de TS certificadas pela Fundação Banco do Brasil (FBB) entre 2007 e 2011. Os dados do estudo provêm do Banco de Tecnologias Sociais, base mantida pela FBB que possui, atualmente, informações cadastradas sobre cerca de mil projetos. Analisando uma amostra de 146 deles que envolviam órgãos públicos municipais (de um universo de 401 TS certificadas à época), os autores informaram que cada TS, para integrar o banco, é avaliada sob 5 critérios a serem atendidos:

1. Estar em atividade há pelo menos dois anos; 2. Possuir resultados comprovados de transformação social; 3. Estar sistematizada a ponto de tornar-se possível a reaplicação em outras comunidades; 4. Contar com o envolvimento da comunidade na sua concepção ou ter sido apropriada por ela em seu desenvolvimento ou reaplicação; 5. Respeitar os seguintes princípios e valores: protagonismo social; respeito cultural; cuidado ambiental; e solidariedade econômica. (GAPINSKI; FREITAS, 2016, p. 8).

O trabalho foi referência para o desenho do MSL, pois contribuiu para reforçar a percepção de que os aspectos metodológicos em geral não são privilegiados, em se tratando de TS, já que, na verificação prévia do teor de cada um dos critérios considerados para a certificação das TS submetidas ao BTS, não foi encontrado nenhum critério relacionado à metodologia usada na produção ou aplicação.

O trabalho de Souza e Rufino (2017) descreveu um levantamento de dados de todos os projetos de pesquisa, de extensão e de ações associadas cadastrados na plataforma virtual institucional Sistema Integrado de Gestão de Atividades Acadêmicas (SIGAA), utilizada, em grande parte, pelas Universidades e IFs que envolviam inovações e TS concluídas ou em andamento. Junto a isso, informou que parte significativa dos projetos de extensão voltados para TS não correspondiam aos critérios esperados para considerá-los efetivamente como TS. Dos 108 projetos levantados no trabalho, apenas 15 foram identificados como sendo efetivamente TS; os três principais fatores de exclusão foram: 1) plano de trabalho pouco ou não participativo; 2) cronograma de ações impositivo; e 3) dependência técnica.

O trabalho contribuiu ainda, com seus parâmetros de avaliação de projetos, para a criação dos critérios de inclusão de trabalhos e na categorização dos dados do MSL empreendido na pesquisa, com destaque para a relevância do plano de trabalho participativo da comunidade e dos tipos de dinâmica de colaboração entre os agentes como decisivos para caracterizar o projeto como efetivamente uma TS.

Delimitou-se como problema de pesquisa a ausência de recursos específicos de orientação metodológica para o desenvolvimento de TS voltados aos docentes dos IFs, e tomou-se, como desenho de solução, a condução de um MSL sobre projetos de TS no Brasil, com foco em suas metodologias, suas etapas e seus procedimentos de desenvolvimento, seguido de uma análise qualitativa - Análise Temática - dos resultados do Mapeamento referentes às descobertas metodológicas, cuja sistematização final subsidiou a criação de um produto educacional de formação docente em TS no sentido de apoiar e ampliar a sua produção por meio de projetos de extensão no contexto dos IFs.

A metodologia da pesquisa foi de natureza aplicada, com objetivos exploratórios e descritivos dos conceitos, das características e das etapas de desenvolvimento de TS analisadas, e a abordagem foi qualiquantitava. O desenho metodológico segue representado na Figura 1. 
Figura 1 - Desenho metodológico da pesquisa.

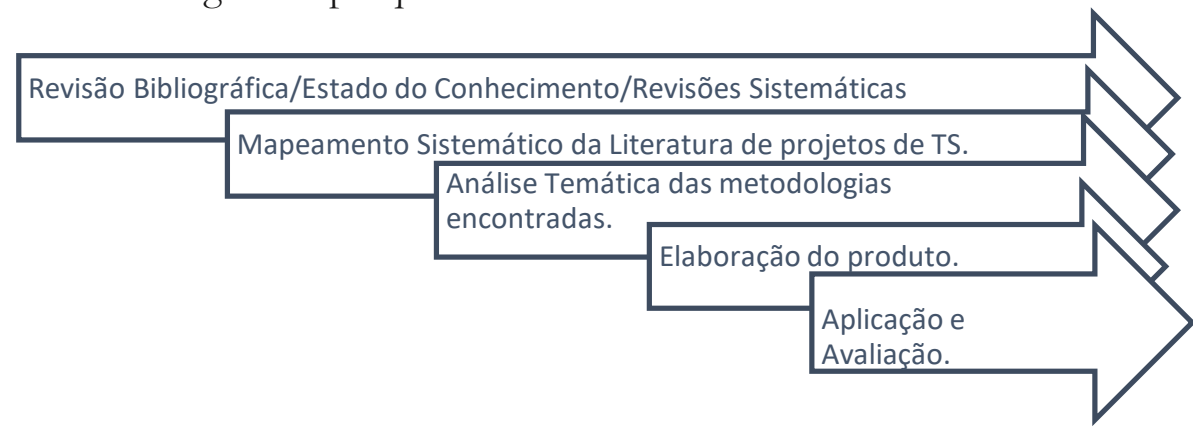

Fonte: Elaborado pelos autores.

A partir da discussão dos resultados do MSL, conduziu-se uma Análise Temática para analisar padrões significativos do conjunto de dados sobre metodologia de produção de TS que auxiliassem a traçar trilhas de desenvolvimento transponíveis didaticamente para o produto educacional. Os principais resultados da pesquisa foram reunidos no sentido de oportunizar a compreensão dos conceitos e das características fundamentais das TS e a construção colaborativa de um projeto de extensão em TS, a ser aplicado pelos participantes em seus Campi de atuação no IFS. As etapas de aplicação e a avaliação do produto foram realizadas no Campus Lagarto do IFS, por meio de um Estudo de Caso.

\section{Condução do MSL}

Em face da escassez de informações sobre o desenvolvimento prático de projetos de TS, foi definido o seguinte escopo para o MSL: artigos científicos revisados por pares e publicados em periódicos indexados em bases de dados reconhecidas pela comunidade científica entre 2013 e 2017 - período em que, por meio de testes preliminares de busca em bases de dados relevantes para o tema, foi identificada uma quantidade significativa de artigos que abordavam TS de algum modo - que descrevessem projetos concretos de TS desenvolvidas em comunidades brasileiras e indicassem informações de natureza metodológica (processos, etapas e/ou procedimentos) de produção, aplicação e/ou reaplicação das TS. O protocolo do MSL seguiu o modelo proposto por Petersen (2008) e adaptado por Dias Jr. Et al (2013), conforme a Figura 2.

Figura 2 - Processo de Mapeamento Sistemático segundo Petersen.

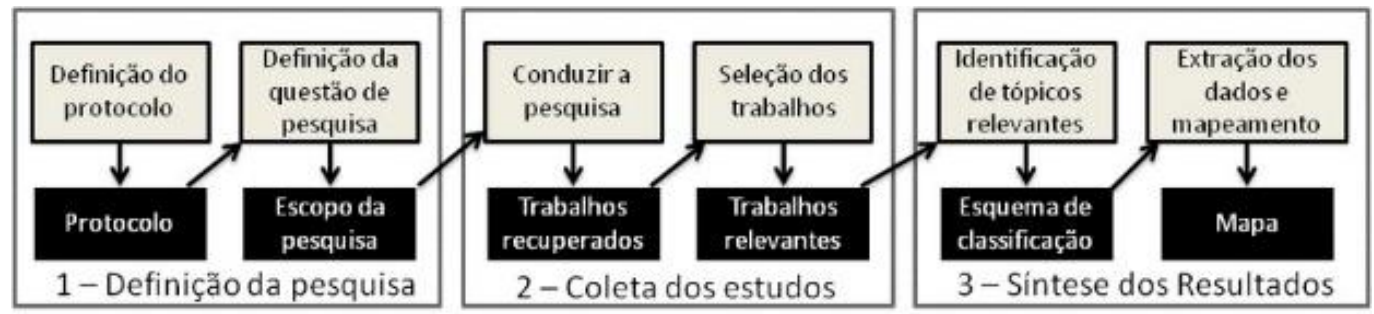

Fonte: (DIAS JR. Et al, 2013).

Os critérios indicados no Quadro 1 foram definidos no sentido de refletirem o recorte adequado em relação ao objeto, ao escopo e ao problema de pesquisa, evitando a seleção de trabalhos irrelevantes para o objetivo final de elaboração do produto educacional, notadamente artigos que não abordassem a aplicação prática de projetos de TS na realidade social, posto que o levantamento da produção teórica em livros, dissertações e teses sobre o tema das TS já havia sido empreendido. 
Quadro 1 - Critérios de inclusão e exclusão

\begin{tabular}{|c|c|}
\hline Critérios de Inclusão (CI) & Critérios de Exclusão (CE) \\
\hline $\begin{array}{l}\text { CI1 - Publicações que abordam experiências de produção, } \\
\text { aplicação e/ou reaplicação de Tecnologias Sociais no Brasil } \\
\text { e evidenciam a metodologia utilizada. }\end{array}$ & $\begin{array}{l}\text { CE1 - Documentos que só estão disponíveis na forma de } \\
\text { relatórios de workshop/conferência, resumos, entrevistas, } \\
\text { apresentações em PowerPoint ou estudos secundários, } \\
\text { assim como Capítulos de livros, dissertações, teses e } \\
\text { artigos publicados sem revisões. }\end{array}$ \\
\hline $\begin{array}{l}\text { CI2 - Artigos publicados em periódicos, conferências ou } \\
\text { revistas revisadas por pares. }\end{array}$ & $\begin{array}{l}\text { CE2 - Estudos fora do escopo desta pesquisa, tais como: } \\
\text { os que abordam Tecnologias Sociais exclusivamente em } \\
\text { contextos administrativos, empresariais, econômico- } \\
\text { financeiros ou sob a perspectiva unicamente das políticas } \\
\text { públicas; artigos que tratam do tema exclusivamente sob a } \\
\text { perspectiva teórica e/ou histórica, trabalhos que } \\
\text { tangenciam o conceito de Tecnologias Sociais de modo } \\
\text { muito genérico ou remoto sem abordar nenhuma } \\
\text { experiência concreta de Tecnologias Sociais. }\end{array}$ \\
\hline CI3 - Publicações entre 2013 e 2017. & $\begin{array}{l}\text { CE3 - Trabalhos duplicados, que aparecem nas buscas em } \\
\text { duas ou mais bases de dados. }\end{array}$ \\
\hline CI4 - Artigos em português ou inglês. & $\begin{array}{l}\text { CE4 - Artigos escritos em outras línguas que não } \\
\text { português e inglês. }\end{array}$ \\
\hline $\begin{array}{l}\text { CI5 - Quando mais de um artigo descrever a mesma } \\
\text { Tecnologia Social, apenas o mais recente será incluído. }\end{array}$ & $\begin{array}{l}\text { CE5 - Artigos mais antigos quanto ao ano de publicação } \\
\text { nos casos de dois ou mais artigos tratarem da mesma } \\
\text { Tecnologia Social. }\end{array}$ \\
\hline $\begin{array}{l}\text { CI6 - Quando um artigo abordar mais de uma Tecnologia } \\
\text { Social, será levada em conta a desenvolvida em período } \\
\text { mais recente e/ou a que informar mais dados referentes às } \\
\text { categorias de extração de dados estabelecidas. }\end{array}$ & $\begin{array}{l}\text { CE6 - Tecnologias Sociais desenvolvidas em períodos } \\
\text { menos recentes, no caso de artigos que abordam mais que } \\
\text { uma Tecnologia Social, serão excluídos, exceto nos casos } \\
\text { em que a menos recente informe mais dados referentes às } \\
\text { categorias de extração de dados estabelecidas. }\end{array}$ \\
\hline
\end{tabular}

Fonte: Elaborado pelos autores.

A condução do MSL passou pela definição da string e das estratégias de busca e seleção dos artigos, assim como o estabelecimento de processos detalhados de extração de dados dos artigos selecionados, que constituíram um protocolo representado pela Figura 3 a seguir.

Figura 3 - Protocolo de seleção de documentos

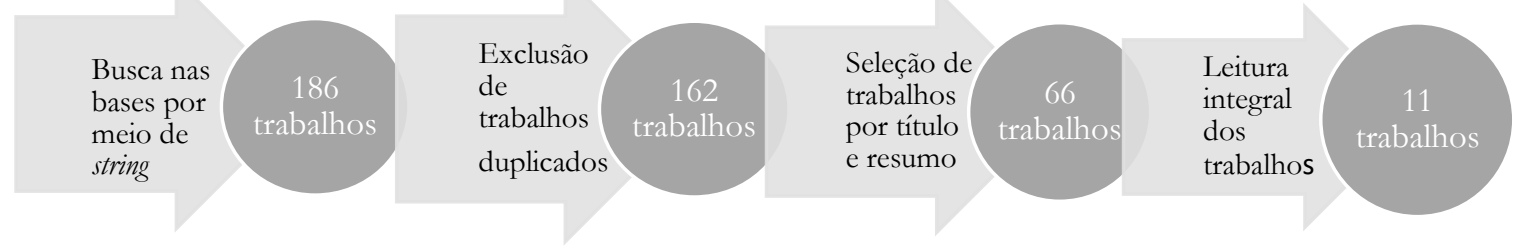

Fonte: Elaborado pelos autores.

Observa-se, na Figura 3, que dos 186 estudos retornados na primeira etapa, restaram apenas 11 , cerca de $5,9 \%$ do total, o que pode em parte dever-se ao fato de que a maioria dos artigos retornados, apesar de incluírem o termo TS, tratavam o conceito de modo exclusivamente teórico, sem tratar de projetos aplicados na prática, ou referiam-se à TS de modo tangencial, genérico, ou ainda, errôneo, confundindo-a com Empreendedorismo social. 
$\mathrm{Na}$ terceira etapa, foram excluídos tais títulos e resumos; 55 deles por não tratarem de experiência concreta de TS em comunidade específica. Os 11 artigos selecionados são detalhados no Quadro 2.

Quadro 2 - Artigos selecionados para extração de dados

\begin{tabular}{|c|c|c|c|}
\hline TÍTULO & AUTOR & PERIÓDICO & ANO \\
\hline $\begin{array}{l}\text { Associações sócio técnicas e } \\
\text { práticas de gestão em } \\
\text { desenvolvimento: analisando } \\
\text { rastros por entre o traçado do } \\
\text { P1MC. }\end{array}$ & $\begin{array}{l}\text { Andrade, J. A.; } \\
\text { Cordeiro Neto, J.R.; } \\
\text { Valadão, J. A. D. }\end{array}$ & Cadernos EBAPE.BR & 2013 \\
\hline $\begin{array}{l}\text { Bases sócio técnicas de uma } \\
\text { tecnologia social: o transladar } \\
\text { da pedagogia da alternância } \\
\text { em Rondônia. }\end{array}$ & $\begin{array}{l}\text { Andrade, J. A.; } \\
\text { Cordeiro Neto, J.R.; } \\
\text { Valadão, J. A. D. }\end{array}$ & $\begin{array}{l}\text { Revista Organizações e } \\
\text { Sociedade. }\end{array}$ & 2017 \\
\hline $\begin{array}{l}\text { Biorremediação vegetal do } \\
\text { esgoto domiciliar: o caso da } \\
\text { fossa verde em comunidades } \\
\text { rurais do alto sertão alagoano. }\end{array}$ & $\begin{array}{l}\text { Oliveira Netto, A. P.; } \\
\text { Guerra, L. R. M.; Silva, } \\
\text { M.R.P.; Silva, R. S. }\end{array}$ & $\begin{array}{l}\text { Revista Produção e } \\
\text { Desenvolvimento }\end{array}$ & 2015 \\
\hline $\begin{array}{l}\text { Desenvolvimento sustentável } \\
\text { e inovação social: a reciclagem } \\
\text { sob a perspectiva da } \\
\text { tecnologia social }\end{array}$ & $\begin{array}{l}\text { Horst, L. V. M.; Freitas, C. } \\
\text { C. G. }\end{array}$ & $\begin{array}{l}\text { Revista Tecnologia e } \\
\text { Sociedade }\end{array}$ & 2016 \\
\hline $\begin{array}{l}\text { Diagnóstico participativo } \\
\text { socioambiental e de riscos à } \\
\text { saúde das comunidades do } \\
\text { entorno do Complexo } \\
\text { Petroquímico do Rio de } \\
\text { Janeiro, Brasil. }\end{array}$ & $\begin{array}{l}\text { Moniz, M. A.; Saboia, V. M.; } \\
\text { Carmo, C. N.; Hacon, S. S. }\end{array}$ & Ciência e Saúde coletiva & 2017 \\
\hline $\begin{array}{l}\text { Produção colaborativa e } \\
\text { convergência de mídia na TV: } \\
\text { uma proposta de inovação e } \\
\text { tecnologia social para as TVs } \\
\text { universitárias. }\end{array}$ & $\begin{array}{l}\text { Magalhaes, C. M.; Paschoal } \\
\text { Neto, J. D.; Magalhaes, C. } \\
\text { M.; Paschoal Neto, J. D. }\end{array}$ & $\begin{array}{l}\text { Revista da Avaliação da } \\
\text { Educação Superior. }\end{array}$ & 2013 \\
\hline $\begin{array}{l}\text { Proposta metodológica para } \\
\text { redesenho de comunidades } \\
\text { informais - construção da } \\
\text { resiliência diante do estresse } \\
\text { hídrico. }\end{array}$ & Cerqueira, L. F.; Silva, F. L. & Ambiente \& Sociedade. & 2016 \\
\hline $\begin{array}{l}\text { Representações Sociais da } \\
\text { Água e Tecnologias Sociais. }\end{array}$ & Polli, G. M.; Kuhnen, A. & Psico (PUC - RS) & 2013 \\
\hline $\begin{array}{l}\text { Tecnologia Social, } \\
\text { Universidade e Sociedade: a } \\
\text { Extensão como Espaço } \\
\text { Estratégico de Intervenção. }\end{array}$ & Oliveira, E. M. & $\begin{array}{l}\text { Revista Tecnologia e } \\
\text { Sociedade }\end{array}$ & 2013 \\
\hline $\begin{array}{l}\text { Tecnologias Sociais aplicadas } \\
\text { a Política Nacional de } \\
\text { Resíduos Sólidos: gestão } \\
\text { integrada de resíduos sólidos } \\
\text { no campo. }\end{array}$ & $\begin{array}{l}\text { Oliveira, G. K. L. P.; Santos, } \\
\text { N. }\end{array}$ & $\begin{array}{l}\text { Revista de Direito e } \\
\text { Sustentabilidade }\end{array}$ & 2016 \\
\hline $\begin{array}{l}\text { Viabilidade de uso de } \\
\text { biodigestor continuo: um } \\
\text { estudo de caso na comunidade } \\
\text { Arara, município de Tavares - } \\
\text { PB. }\end{array}$ & Silva, M. L C.; Araijo, A. O. & $\begin{array}{l}\text { Revista de Geografia e } \\
\text { Interdisciplinaridade. }\end{array}$ & 2016 \\
\hline
\end{tabular}

Fonte: Elaborado pelos autores.

Estabeleceu-se previamente uma classificação em categorias e subcategorias de dados a serem extraídos dos artigos selecionados, a fim de melhor responder às questões de pesquisa. As primeiras 4 categorias referiram-se à caracterização geral das TS mapeadas, como Tipo de demanda/problema social; Tipo de Tecnologia Social/solução; Local de aplicação da TS; e Período de desenvolvimento/aplicação da TS. As categorias 5 e 6 referiram-se aos atores sociais e às dinâmicas de 
parceria e colaboração na distribuição de ações e tarefas envolvidos na TS.

Identificou-se, no decorrer da extração de dados, que todos os artigos selecionados indicaram redes de atores com composições híbridas, ou seja, com tipos diferentes de atores sociais; em nenhum foi identificado um tipo de ator social isolado atuando na TS abordada, e a comunidade local - ator social interno - integrava todas as composições encontradas.

A partir das descobertas sobre os tipos de dinâmicas de colaboração entre os atores das TS descritas nos artigos, construiu-se uma subcategorização para tais padrões de mediações relacionais entre os atores - Centralidade da comunidade, Produção participativa, Interesses combinados, Teoria das relações sociais - no sentido de investigar, mais adiante, o eventual vínculo entre tais tipos de relação e os tipos de metodologia de desenvolvimento da TS.

A categoria 7 traduziu o foco principal do Mapeamento: Tipo de Metodologia de produção da TS - Métodos, processos, procedimentos, etapas e/ou critérios sócio técnicos de produção/aplicação da TS. Essa categoria foi classificada, mediante as informações identificadas, nas subcategorias: Metodologias próprias; Pesquisa-ação; Pesquisa-ação + LIUDD; Pedagogia da alternância.

A subcategoria "Metodologias próprias" foi criada durante a pesquisa para nomear as diversas metodologias, especialmente criadas para o desenvolvimento de cada TS abordada, em seus contextos específicos. Tal categoria revelou-se predominante nos estudos mapeados.

Ao longo da pesquisa, identificou-se uma aderência significativa entre conceitos e características da TS enunciadas por diversos autores presentes nas referências teóricas pesquisadas; como a de ser uma solução construída a partir dos problemas e da visão da própria comunidade, e o desenho de métodos próprios a cada grupo de atores sociais envolvidos no projeto, que, desse modo, constroem coletivamente processos e etapas de produção e aplicação da TS, conforme cada realidade social local, perfil e demandas da comunidade. Não foram encontrados, na literatura pesquisada, nenhum outro termo ou definição para esse tipo de metodologia, o que nos levou a propor o termo "Metodologias próprias".

Por fim, a categoria 8 referiu-se ao Tipo de método de reaplicação da TS em outros contextos, classificada nas subcategorias: Sistematizada com cada comunidade, Adequação Sociotécnica (AST) + Construtivismo Social da Tecnologia (CST); Modelo Indiano de Fluxo Contínuo.

Destaca-se que qualquer aplicação de TS envolve, de alguma maneira, um processo de adequação sociotécnica (DAGNINO, 2010), assim, em TS, não se usa o conceito de replicação, mas de reaplicação, considerando que em cada contexto diferente a TS terá de ser reprojetada (JESUS; COSTA, 2013, p. 22). A prevalência de "Metodologias próprias" nas TS abordadas aponta para um alinhamento com a noção de que reaplicá-las em outras comunidades seria, de fato, reprojetá-las inteiramente.

Os dados dos artigos selecionados foram extraídos durante a leitura integral segundo as categorias estabelecidas e, à análise quantitativa dos resultados do MSL sucedeu-se a realização de uma análise qualitativa por meio de uma Análise Temática (AT) das informações relacionadas exclusivamente à categoria "Tipos de metodologia de desenvolvimento de TS".

Esse método de análise, segundo Braun e Clarke (2006), é de caráter qualitativo e aplicado a um conjunto de dados a fim de identificar, analisar e reportar padrões significativos, características que contribuíram significativamente para subsidiar os processos de seleção, organização, sistematização e transposição didática de conteúdos para o produto educacional de formação docente em TS.

\section{Condução da Análise Temática}

A AT foi conduzida por meio das 6 etapas apresentadas na Figura 4 a seguir. 
Figura 4 - Etapas de condução da Análise Temática

$\left.\left.\begin{array}{l}\text { Familiarização com os } \\ \text { dados }\end{array}>\begin{array}{c}\text { Geração de } \\ \text { códigos } \\ \text { iniciais }\end{array}\right\rangle \begin{array}{c}\text { Busca por } \\ \text { temas }\end{array}>\begin{array}{c}\text { Revisão dos } \\ \text { temas }\end{array}>\begin{array}{c}\text { Delimitação/ } \\ \text { nomeação dos } \\ \text { temas }\end{array}\right\rangle$

Fonte: Elaborado pelos autores com base nas etapas de condução de análises temáticas propostas por (BRAUN; CLARKE, 2006, p. 77-101).

Com base no fluxo representado na Figura 4, iniciou-se na AT conduzida na pesquisa a etapa 1, de familiarização com os dados; com a releitura, nos artigos mapeados, das informações referentes aos tipos de metodologia de desenvolvimento de TS no sentido de conhecê-los a fundo.

$\mathrm{Na}$ etapa 2, de geração de códigos iniciais, realizou-se uma codificação sistemática de todo o texto dos artigos mapeados anteriormente usando destaques de trechos, anotações e comentários no sentido de reconhecer padrões e reunir, sob um mesmo código ou rótulo, as informações semelhantes ou próximas relativas a cada subcategoria específica de tipo de metodologia.

Nessa etapa, os códigos adotados foram os mesmos das subcategorias criadas no MSL, posto que traduziam os subtipos de metodologia de desenvolvimento de TS encontrados no conjunto de dados dos artigos mapeados, com destaque para as "Metodologias próprias".

$\mathrm{Na}$ etapa 3, de busca por temas, partindo da codificação realizada na etapa anterior, reuniram-se vários códigos em torno de potenciais temas ou subtemas, usando o recurso de mapas mentais para expor visualmente as relações entre temas e subtemas que representavam padrões encontrados nos dados textuais dos artigos. Buscou-se por temas que tivessem significado padronizado dentro do conjunto de dados extraídos no Mapeamento e que captassem algo relevante para responder à questão principal da pesquisa, como informações sobre processos e/ou etapas/fases aplicadas de cada tipo de metodologia de desenvolvimento indicado nos códigos estabelecidos anteriormente. Chegou-se, então, ao primeiro resultado relevante, a síntese temática preliminar representada na figura 5 a seguir.

Figura 5 - Síntese Temática

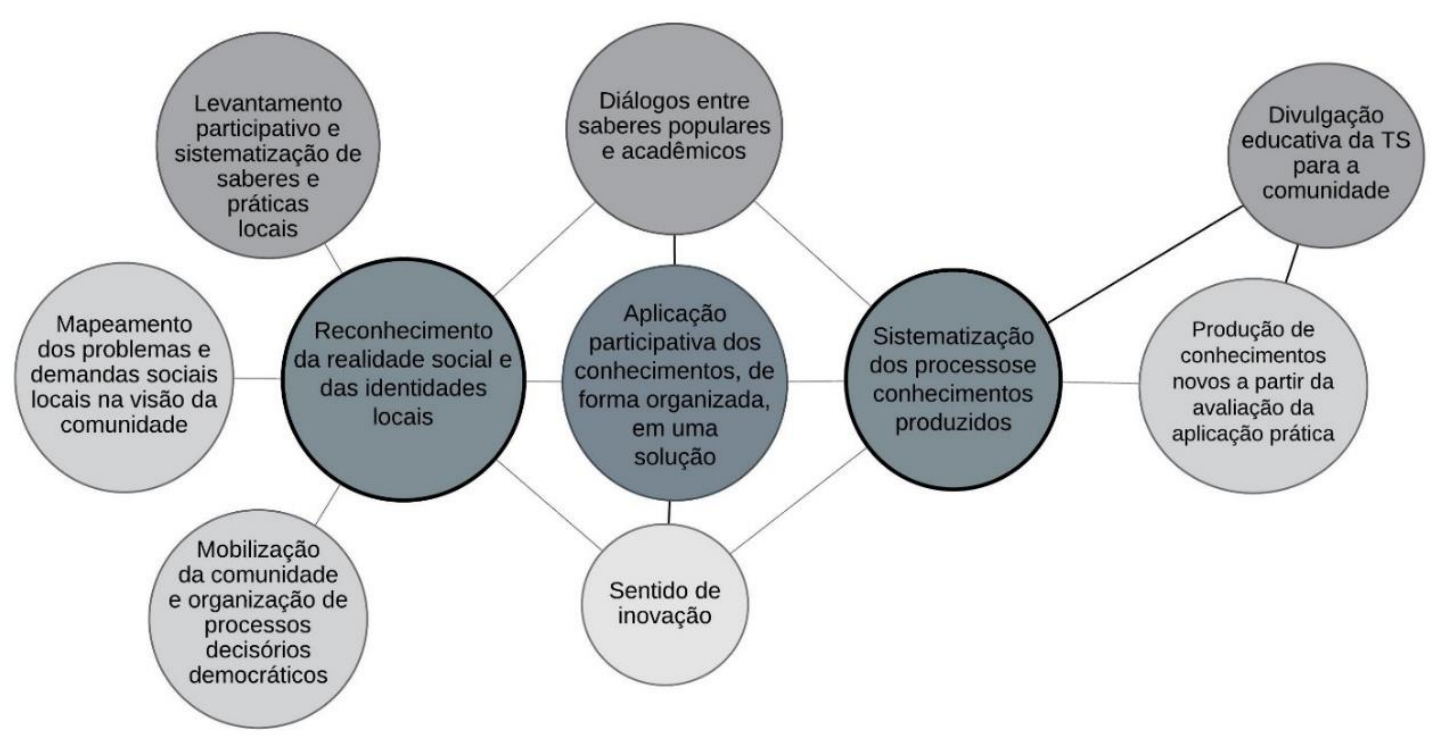

No mapa mental apresentado na Figura 5, os 3 círculos centrais, os mais escuros, representam temas que correspondem a fases ou etapas descobertas na maioria das descrições de 
desenvolvimento de TS presentes nos artigos mapeados e confrontadas com categorias teoricamente estabelecidas em trabalhos sobre análise de características de TS, sobretudo o de Garcia (2007), que destaca características ligadas às dimensões do Conhecimento, ciência e tecnologia e inovação; Educação; Participação, cidadania e democracia; e Relevância social.

Há uma fase inicial, a de "Reconhecimento da realidade social e das identidades locais de cada comunidade-alvo"; essa deriva em subtemas correlatos, desenvolvidos de modo diferente a depender da TS específica abordada, os quais são identificados sob rótulos sistematizados ao longo da análise, tais como "Levantamento e sistematização dos saberes e práticas locais junto à comunidade"; "Mapeamento das demandas sociais locais sob o ponto de vista da comunidade"; e "Mobilização e organização da comunidade". Há uma fase intermediária, a de "Aplicação participativa dos conhecimentos de forma organizada em uma solução" para as demandas da comunidade - a solução constitui-se na TS sistematizada e desenvolvida; fase esta que também se relaciona a subtemas correlatos, os quais caracterizam o modo como a fase se dá em cada TS, transpostas na pesquisa como "Diálogo entre saberes populares e acadêmicos" e "Sentido de inovação" do projeto. E, por fim, há a "Sistematização dos processos e conhecimentos produzidos" ao longo do desenvolvimento da TS, fase importante para a apropriação de saberes por parte da comunidade; relacionada ao subtema sistematizado ao longo da análise como "Avaliação e produção de conhecimentos", realizada a partir da aplicação prática da TS, sua avaliação e divulgação para a comunidade.

Em seguida, foi realizada a $4^{a}$ etapa, a de Revisão dos temas - representado na Figura 6 a seguir -, com uma reorganização dos temas e subtemas levantados no sentido de chegar a temas-padrão coerentes, que representassem sinteticamente as fases de um processo ou fluxo de produção de TS de acordo com o corpus de dados analisado e que pudessem orientar o desenvolvimento do produto educacional.

Figura 6 - Síntese temática revisada

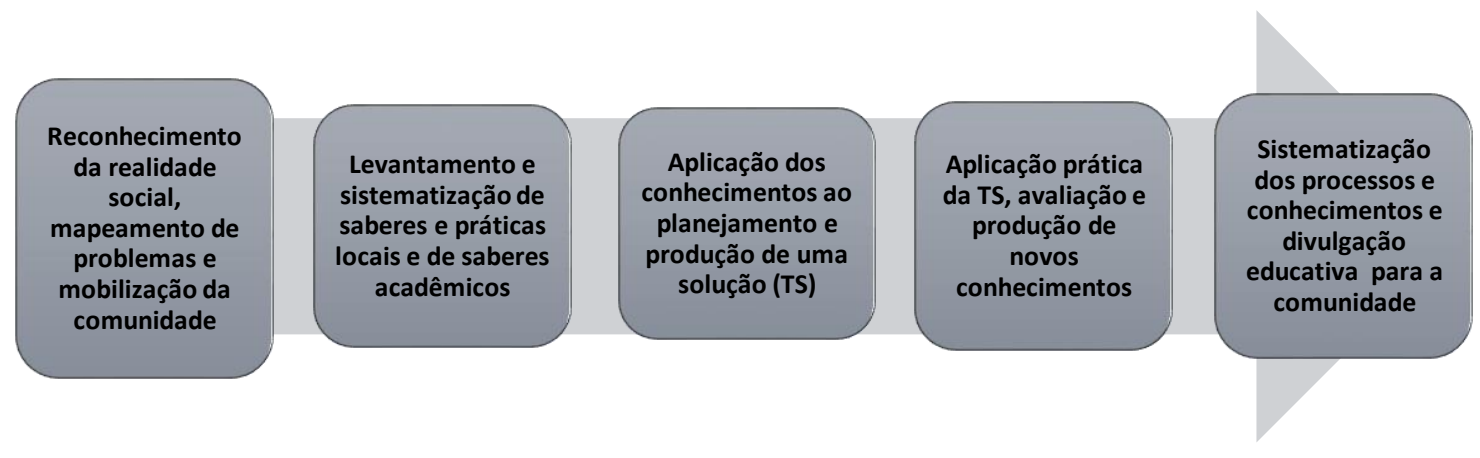

Fonte: Elaborado pelos autores.

É importante notar, porém, que esse fluxo geral de processos, sugerido pela síntese temática revisada, não indica, ainda, as sequências práticas específicas a serem adotadas para desenvolver cada processo e obter os resultados desejados. Não há como saber por meio do fluxo, por exemplo, quais etapas, procedimentos e instrumentos específicos podem ser aplicados para mapear, reconhecer ou mobilizar a comunidade, ou para levantar os saberes e práticas locais etc.

Para buscar a identificação de tais procedimentos, usamos o fluxo como uma chave de análise dos resultados da pesquisa relacionados a aspectos metodológicos. Desse modo, foi possível reconhecer como os atores sociais envolvidos nas experiências analisadas procederam, ao longo de cada projeto, para encaminhar as etapas de desenvolvimento da TS. 
Na etapa 5 da metodologia de Análise Temática, é realizada a "Delimitação e nomeação de temas", na qual buscou-se a essência de cada um - sem perder a ordenação, organização deles, sugerida pelo fluxo - e obteve-se, assim, o mapa final de temas, nomeados sinteticamente, porém coerentes e expressivos de significado no conjunto de dados analisado, de modo a contribuir mais claramente para o propósito da pesquisa. Essa síntese temática final está representada na Figura 7, a seguir.

Figura 7 - Síntese temática final

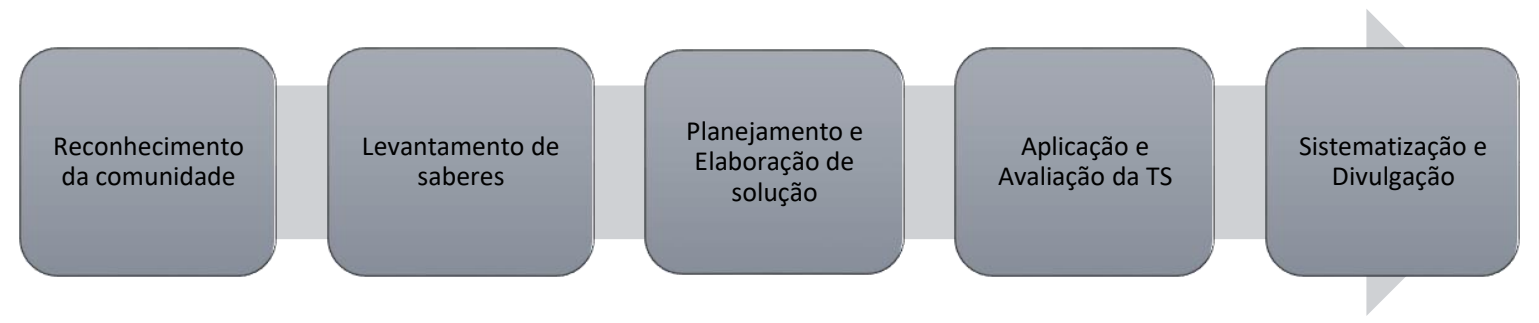

Fonte: Elaborado pelos autores.

$\mathrm{Na}$ Figura 7, cada tema corresponde a uma etapa de desenvolvimento de TS, disposta em um fluxo geral de produção e aplicação desse tipo de projeto, conforme a análise qualitativa dos trabalhos feita até aqui. É importante notar que os subtemas não foram indicados na síntese temática final por não serem muitos e diversos, posto que, para cada tema (etapa), há várias possibilidades de "sub etapas", processos ou procedimentos de desenvolvimento de TS, a depender do tipo de metodologia seguida e das especificidades de cada TS e cada rede de atores envolvida.

Na etapa 6, a de Produção de relatório da AT, procedeu-se, a partir da síntese temática final, a interpretação dos significados dos temas e das relações que estabelecem entre si de modo a responder com quais procedimentos específicos cada fase de desenvolvimento de TS se deu em cada projeto, apontando, assim, no sentido das possibilidades de construção de fluxos de produção de TS adequadas ao contexto dos IFs e aos objetivos de formação docente.

\section{APRESENTAÇÃO E DISCUSSÃO DOS RESULTADOS}

Os resultados referentes aos tipos de metodologias, etapas, procedimentos, processos ou métodos de desenvolvimento e/ou aplicação encontrados corroboraram a hipótese inicial: a de que é viável encontrar tais tipos de informação por meio de um MSL voltado para a seleção de artigos cujas experiências concretas de TS no Brasil sejam abordadas.

Serão aqui destacados apenas os resultados relativos às metodologias de desenvolvimento de TS, o foco principal da pesquisa, e alguns dos resultados ligados aos atores envolvidos nas TS e as dinâmicas de colaboração que estabelecem entre si. Isso porque que tais resultados se revelaram, sob alguns aspectos, relacionados aos tipos de metodologia empregados nas TS. Os resultados relativos a outras categorias, ligados à caracterização das TS, não farão parte desta seção. Serão também discutidos aqui os principais resultados da AT realizada sobre o recorte de resultados do MSL relevantes para subsidiar a sistematização do produto educacional de formação docente em TS.

\section{Resultados do Mapeamento Sistemático}

Conforme a Figura 8, a seguir, há a prevalência de metodologias próprias, com etapas e procedimentos desenvolvidos especialmente para cada projeto, o que aponta uma possível interpretação 
para a ausência - identificada no levantamento prévio - de materiais de orientação metodológica, como manuais ou guias para o desenvolvimento desse tipo de projeto. Os de TS, por serem de natureza essencialmente participativa, têm seu desenvolvimento guiado muitas vezes por processos criados de forma colaborativa pela rede de agentes sociais neles envolvidos, conforme as demandas específicas de cada comunidade-alvo, como aponta a prevalência das "Metodologias próprias" nos trabalhos.

Figura 8 - Tipos de metodologias de desenvolvimento das TS.

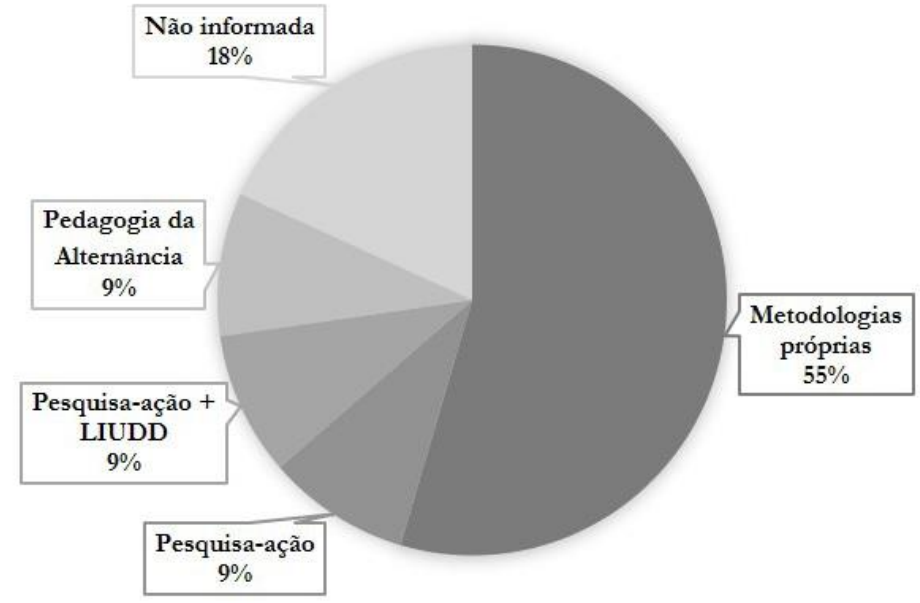

Fonte: Elaborado pelos autores.

Esse cenário intensificou a importância da investigação qualitativa sobre os artigos mapeados quanto às etapas e aos procedimentos das aqui chamadas "Metodologias próprias", no sentido de sistematizar processos de produção de TS igualmente próprios aos contextos e atores sociais dos IFs.

A Figura 8 mostra, ainda, que 18\% das TS baseou-se na Pesquisa-Ação, - 9\% de modo isolado e 9\% somada à LIUDD - metodologia de planejamento urbano de baixo impacto ambiental.

Quanto à composição das redes de atores sociais envolvidos nas TS mapeadas, descobriu-se que todos os tipos de composição de atores encontrados incluíam a Comunidade como membro, o que corrobora a caracterização dos projetos descritos nos estudos selecionados como sendo efetivamente TS, posto que um plano de trabalho pouco ou não participativo é, segundo Souza e Rufino (2017), critério primordial de exclusão de um projeto de intervenção social do rol das TS, e destacou-se como composição predominante, cerca de $37 \%$ do total, a que reúne "Comunidade" e "Pesquisadores de Universidades", sendo que nenhuma rede incluiu pesquisadores de IFs.

É preciso considerar, ainda, que o apoio do poder público foi identificado como muito significativo para o desenvolvimento das TS - cerca de 45\% das composições de rede inclúam representantes do poder público, sobretudo municipal e estadual, sendo que $9 \%$ delas incluíam pesquisadores de Universidades, conforme Figura 9.

Nota-se que profissionais ligados à pesquisa são os atores sociais externos predominantes nas TS abordadas pelos trabalhos, e são eles que, na maior parte dos casos, evidenciam nos estudos os aspectos metodológicos do desenvolvimento das TS e os ligados às dinâmicas de colaboração entre os atores que compõem as redes híbridas de produção e aplicação das TS. 
Figura 9 - Composição das redes de atores sociais.

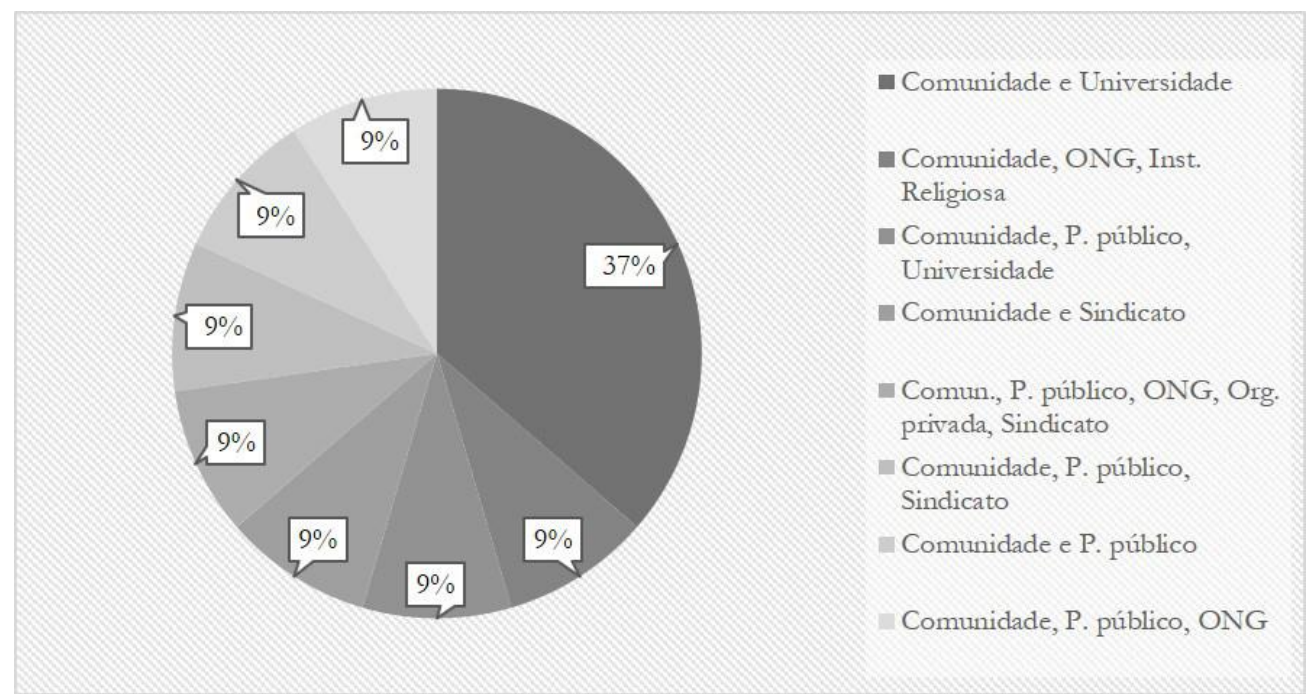

Fonte: Elaborado pelos autores.

Os resultados relativos às dinâmicas de colaboração entre os atores sociais apontam que, apesar de se construírem por meio de critérios e métodos diferentes entre si, todas as dinâmicas passaram pela valorização do papel da comunidade, conforme Figura 10.

Figura 10 - Tipos de dinâmica entre os atores sociais.

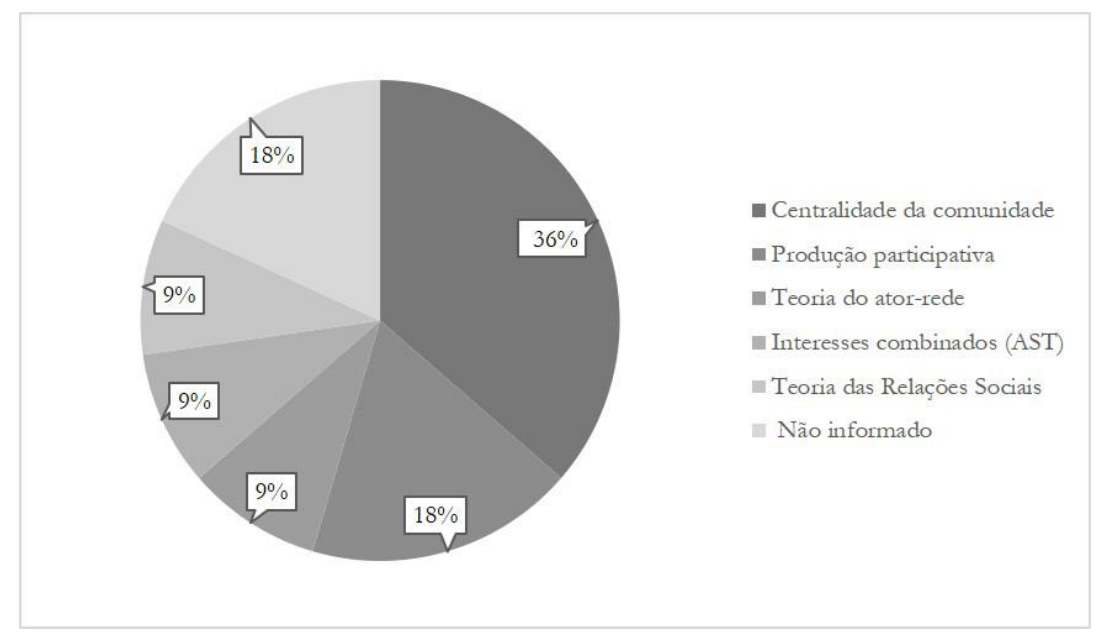

Fonte: Elaborado pelos autores.

Foi relevante, ainda, as descobertas advindas do cruzamento dos resultados de tipos de metodologia de desenvolvimento de TS e tipos de dinâmica entre os atores envolvidos. Conforme a Figura 11, o tipo "Metodologia própria" relacionou-se ao tipo de dinâmica "Centralidade da comunidade" em cerca de $27 \%$ das TS mapeadas, o que pode apontar para o seguinte: quando a comunidade é a protagonista da TS, a rede de atores tende a adotar uma metodologia construída pelo grupo e de acordo com suas expectativas. 
Figura 11 - Cruzamento entre Tipos de dinâmica e Tipos de metodologia

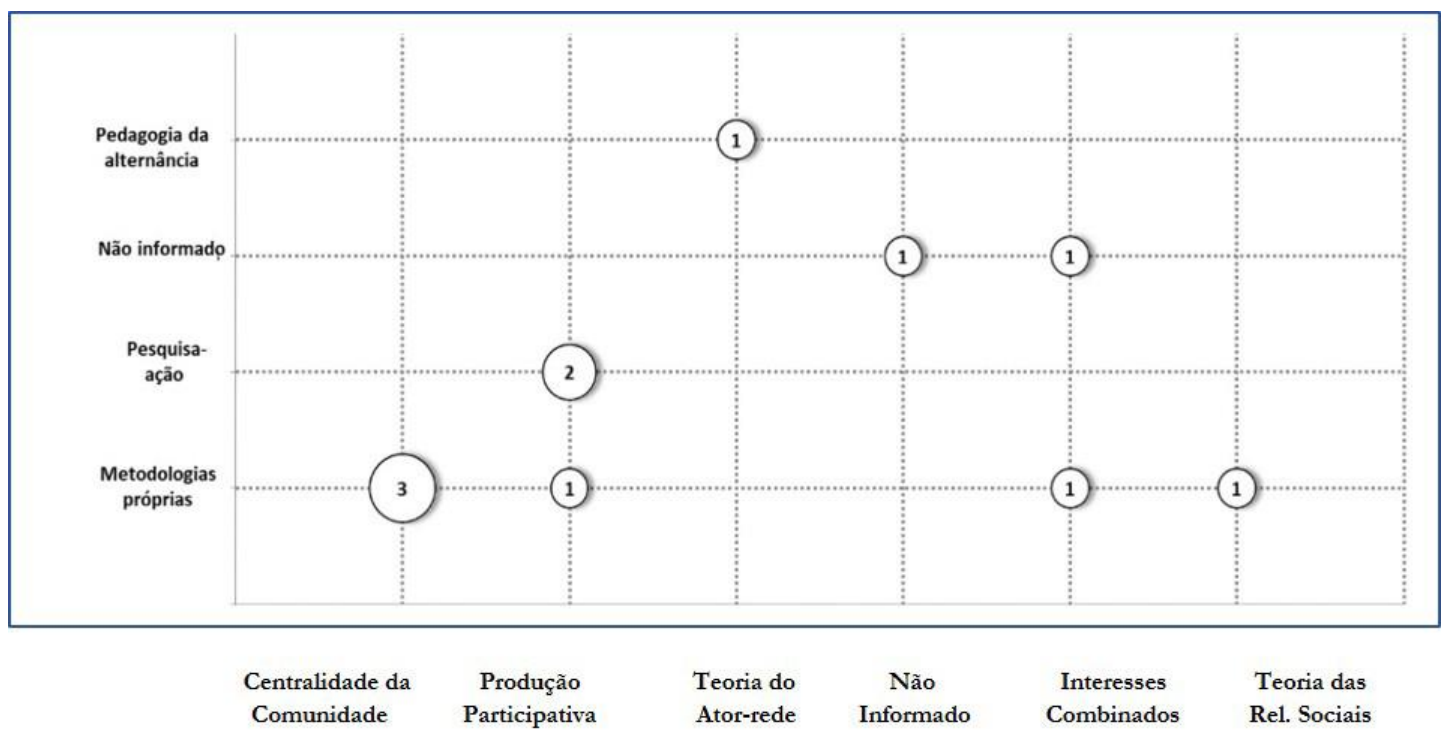

Fonte: Elaborado pelos autores.

Tais descobertas apontaram para a necessidade de elaborar um produto educacional que proporcionasse uma formação para a construção da TS sob a perspectiva da comunidade-alvo e privilegiasse processos de produção de TS desenvolvidos pela própria rede de atores - docentes, discentes e comunidade. Apontaram, também, para a noção de que, para construir uma formação em TS, seria preciso seguir a natureza participativa das próprias TS: compartilhamento de saberes e criação de soluções entre os docentes, ao longo de sua aprendizagem, sob uma lógica semelhante à das Metodologias próprias, identificadas por meio da pesquisa.

Chegou-se, então, à concepção geral do produto como a proposição de trilhas colaborativas de construção de TS adequadas a cada realidade docente e, principalmente, à realidade, aos problemas e à visão de mundo de cada comunidade local, que variam muito em função de cada campus.

Ao final do Mapeamento, apenas 5,9\% dos artigos da amostra analisada evidenciou alguma metodologia, método, processo, sequência, fluxo ou conjunto de etapas aplicadas ao desenvolvimento da TS abordada. Destes, cerca de 55\% indicou o uso de "Metodologias próprias" desenvolvidas especialmente para a TS, que foram então analisadas qualitativamente por meio de uma Análise Temática.

A partir da Síntese Temática Final (Figura 7) já apresentada, que representa uma sequência geral de etapas de desenvolvimento de TS, foram analisados os procedimentos específicos (subtemas) aplicados a cada etapa, em cada TS abordada nos trabalhos que indicaram "Metodologia próprias".

\section{Resultados da Análise Temática}

A variedade de tipos de TS, de demandas das comunidades e de colaboração nas redes de atores envolvidos em cada projeto resultou em sequências de etapas diferentes entre si. Tais sequências foram nomeadas de trilhas de desenvolvimento de TS.

Foram selecionadas, como exemplos, 2 trilhas; cada uma correspondente ao desenvolvimento de uma TS diferente. Ao longo da pesquisa, foram sistematizadas as trilhas das 6 TS baseadas em "Metodologias próprias".

O artigo "Tecnologia Social, Universidade e Sociedade: a Extensão como Espaço Estratégico de Intervenção" (OLIVEIRA, 2013) aborda uma TS de geração de renda, a qual foi 
desenvolvida em um projeto de extensão de pesquisadores de uma incubadora de TS de uma Universidade, em parceria com um grupo de mulheres de um bairro periférico.

Figura 12 - Trilha de desenvolvimento de TS de geração de renda.

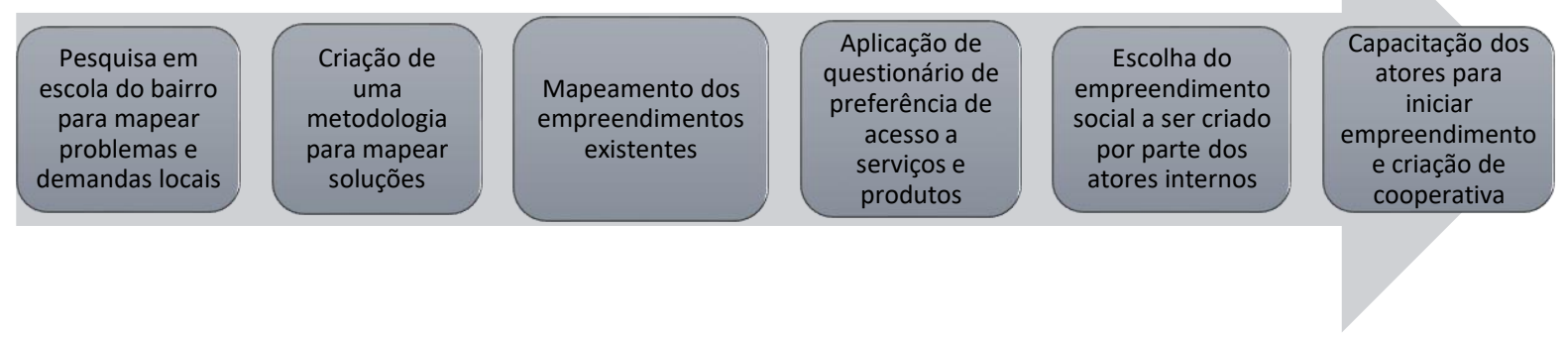

Fonte: Elaborado pelos autores.

A trilha da Figura 12 mostra que a etapa inicial, que corresponderia à de Reconhecimento, foi conduzida por meio de uma pesquisa realizada em uma escola do bairro, que mapeou demandas locais sob a perspectiva das mães e avós dos alunos. Isso porque um levantamento inicial dos pesquisadores mostrou que $60 \%$ das famílias eram monoparentais. Nessa etapa, também foi iniciado o Levantamento de saberes, com entrevistas com as mulheres que diagnosticaram demanda por meios de geração de renda.

A segunda etapa da trilha corresponde à Elaboração de solução e foi realizada com base no diagnóstico da demanda. Os pesquisadores da incubadora criaram nessa etapa um procedimento por eles nomeado de "Territorialização e mapeamento de oportunidade", que consiste em uma metodologia própria de mapeamento diagnóstico de oportunidade de negócios sociais (dentro da metodologia própria mais ampla de desenvolvimento de TS) para apontar possíveis soluções para a demanda. Executada em duas fases, nessa etapa se percebe também elementos de Levantamento de conhecimentos. Na fase 1, os pesquisadores visitaram o bairro para mapear os empreendimentos existentes (quantidade e tipos de atividade); na fase 2, aplicaram um questionário a uma amostra de moradores sobre a quais serviços e produtos gostariam de ter acesso no bairro. A partir dos resultados do mapeamento, as mulheres escolheram o empreendimento social a ser criado: um atelier de costura com recicláveis.

$\mathrm{Na}$ última etapa, ocorreram as ações para a Aplicação da solução (TS), quando os pesquisadores capacitaram as mulheres para iniciar o empreendimento por meio da criação de uma Cooperativa de Mulheres Empreendedoras Sociais em Ação.

No desenvolvimento dessa TS, o grupo de mulheres teve centralidade em todas as etapas, tendo apoio dos pesquisadores para: mapear as oportunidades locais, escolher o empreendimento de maior interesse para elas e para o qual tinham mais habilidade e iniciá-lo de modo que se tornasse sustentável. Além disso, o reconhecimento da realidade local foi feito preliminarmente e os problemas e demandas foram levantados sob a visão dos atores internos da comunidade, não dos pesquisadores externos.

Esse exemplo de trilha para desenvolvimento de TS foi posteriormente transposto para o produto educacional, acompanhado de propostas de reflexão e debate dos docentes sobre: as estratégias utilizadas, em cada fase da TS, quanto à valorização da visão da própria comunidade sobre sua realidade, seus problemas e demandas; sobre a participação e centralidade do grupo de mulheres nas tomadas de decisão no processo de construção da solução (TS); e sobre o apoio técnico-científico que os pesquisadores puderam dar em relação às fases de Elaboração de solução e Aplicação de solução. 
O artigo "Diagnóstico participativo socioambiental e de riscos à saúde das comunidades do entorno do Complexo Petroquímico do Rio de Janeiro, Brasil" (MONIZ et al, 2017), aborda uma TS de planejamento de ações e políticas de gestão ambiental participativa.

Figura 13 - Trilha de desenvolvimento de TS de gestão ambiental.
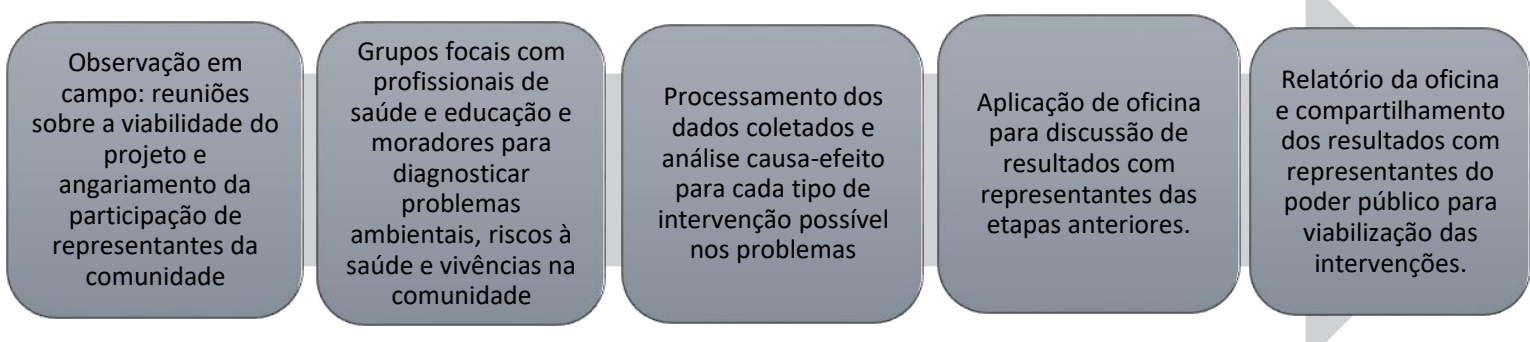

Fonte: Elaborado pelos autores.

O que corresponderia à etapa de Reconhecimento foi realizado por meio das duas primeiras etapas da trilha; na primeira, os pesquisadores (atores externos) empreenderam uma observação em campo para se aproximarem dos representantes da comunidade e para descobrirem, por meio de reuniões, se o projeto teria viabilidade concreta e se os moradores concordariam em participar da TS.

$\mathrm{Na}$ segunda etapa, os problemas da comunidade e suas demandas foram identificados por meio de um mapeamento das percepções de atores internos - moradores e profissionais de saúde e educação que atuam no local -, feito por meio de discussões em Grupos Focais, em relação ao meio ambiente local. Nota-se que o tema de degradação ambiental e seus consequentes riscos prioritários à saúde dos moradores foram pré-definidos pelos pesquisadores, de acordo com a concepção prévia da necessidade de proteção dos ecossistemas e do ambiente social em comunidades que viveram recentes e profundas transformações socioambientais, como é o caso da comunidade alvo da TS, que vive no entorno de um complexo petroquímico.

A terceira etapa dessa trilha corresponde ao Planejamento e Elaboração da solução. Nessa etapa, foi sistematizado o conhecimento adquirido nas etapas iniciais, com o processamento dos dados coletados, a análise causa-efeito para cada tipo de intervenção possível nos problemas mapeados e a realização de uma oficina para discussão de resultados, com representantes da comunidade envolvidos nas etapas anteriores; o que auxiliou na elaboração da solução e garantiu a Divulgação e a aprendizagem do que havia sido construído por parte dos representantes da comunidade.

A última etapa foi de sistematização de um relatório dos resultados da oficina e da discussão e seu compartilhamento com representantes do poder público municipal envolvidos na $1^{\mathrm{a}}$ etapa, com objetivo de viabilizar a Aplicação da TS. Esta parece contribuir também para a Elaboração de solução e para a Divulgação da TS, além de preparar a etapa de Aplicação da TS com apoio operacional do poder público local. Não foram, porém, descritas a elaboração da TS e nem sua Aplicação prática, e não foram indicados procedimentos de Avaliação da aplicação da TS.

Sob a perspectiva das etapas gerais apresentadas na Síntese Temática, resultado de sua quinta etapa, notou-se que algumas das 6 trilhas de desenvolvimento de TS identificadas nos trabalhos analisados, e sistematizadas ao longo da AT, apresentam uma etapa inicial em que não procedeu um verdadeiro Reconhecimento da realidade social da comunidade, nem um mapeamento participativo de seus problemas. Nesses casos, parece que o "problema" foi proposto de antemão pelos atores sociais externos, o que contraria um dos critérios fundamentais para um projeto ser caracterizado como TS. 
Em algumas trilhas, observou-se um detalhamento maior dos processos de desenvolvimento da TS e do compartilhamento dos conhecimentos produzidos por meio de ações educativas na comunidade e, em outras trilhas, verificou-se um fluxo mais relacionado à reaplicação de uma TS já desenvolvida em outra comunidade, e não do desenvolvimento de uma TS nova.

As questões relativas à variedade de etapas e procedimentos de desenvolvimento de TS encontradas, assim como as trilhas de Metodologias próprias sistematizadas a partir da AT, foram fundamentais para o desenvolvimento do produto educacional de formação docente.

\section{Aplicação dos resultados: Produto educacional de formação docente em TS}

Os resultados da pesquisa foram aplicados ao produto educacional de modo a contribuir para o desenvolvimento educativo integral das pessoas envolvidas na produção da TS enquanto instrumento de flexibilização da hierarquia entre os saberes, sob um prisma dialético e inclusivo, de construção de aprendizagens e conhecimentos coletivo (LATOUR, 1994). Isso possibilitou os processos socioculturais de geração, compartilhamento e divulgação de conhecimentos, incluindo os tácitos, e favoreceu - sob a lógica participativa de geração de conhecimentos análoga à das próprias TS - o desenvolvimento de projetos plenamente adequados a cada contexto local, não só no que concerne a cada comunidade do entorno de cada campus, mas também ajustável às particularidades das ações docentes e da organização do trabalho pedagógico.

Para isso, foram transpostos didaticamente ao produto educacional - um minicurso digital interativo na modalidade EAD, disponibilizado na plataforma Moodle -, além de informações gerais sobre as TS e suas relações com a ciência, a tecnologia e o desenvolvimento social, as orientações metodológicas e práticas de desenvolvimento de TS por meio do recurso das "trilhas de desenvolvimento de TS”, criadas ao longo da pesquisa e baseadas nos projetos reais pesquisados.

Tais trilhas representam sequências viáveis e validadas de produção e aplicação desse tipo de projeto, porém adaptáveis às necessidades de cada contexto, podendo constituir-se no eixo práxico, aventado por Kuenzer (1999), a orientar a estruturação de projetos de extenção tecnológica nos IFs.

Por outro lado, a concepção de trilha elaborada na pesquisa representa também uma via para a aprendizagem colaborativa dos docentes por meio do minicurso e uma forma de estimular a constituição de comunidades de aprendizagem, que possam reunir docentes, técnicos, discentes e atores da comunidade local durante os processos que permeiam a produção e a aplicação de TS.

Segundo Tennant e Pogson (1995), recursos de formação docente devem direcionar o aprendizado dos novos conhecimentos para a construção de um sentido para as experiências docentes e para uma reflexão sobre as práticas pedagógicas balizada nos novos saberes adquiridos. Na mesma direção, Zeichner (2008) afirma que a reflexão pedagógica deve passar pelo reconhecimento das experiências práticas e pelo contextos sociais de professores e alunos (ZEICHNER, 2008, p. 543-544), o que pode resultar em uma atitude coletiva de construção de uma comunidade de aprendizagem cujo crescimento mútuo possa ser apoiado e, consequentemente, incitar transformações, não apenas nos processos de ensino e aprendizagem, como também nas instituições de ensino e na sociedade.

Nesse sentido, no produto "Minicurso de Formação Docente em TS", buscou-se propostas didáticas de construção colaborativa de conhecimentos flexíveis e adaptáveis às práticas de ensino dos participantes e de suas realidades educacionais e sociais locais, no intuito de dar sentido às diferentes experiências docentes. São exemplo disso as propostas didáticas de produção coletiva de trilhas inéditas de desenvolvimento colaborativo de TS, por parte dos docentes, com base nas trilhas sistematizadas na pesquisa e apresentadas como modelos cambiáveis no minicurso. 
O desenho das demais situações de aprendizagem do minicurso baseou-se em princípios da aprendizagem ativa e colaborativa e na oportunização da reflexão, sob perspectiva emancipatória, sobre os novos conhecimentos adquiridos. Foram usadas noções ligadas à aprendizagem dialógica e à formação de comunidades de aprendizagem, assim como estratégias inspiradas no modelo de metodologia ativa hands-on-tec (ROSA et al, 2013) - cuja tradução seria algo como "Mãos na tecnologia" -; proposta adaptada da técnica Hands-on (CHEVALÉRIAS, 2002), que foca em situações de aplicação prática dos conhecimentos teóricos, de modo a articular essas duas esferas do saber e produzir soluções para problemas reais, à semelhança do próprio processo de desenvolvimento de TS.

Esse modelo alia princípios das metodologia ativas de estímulo das descobertas e da produção coletiva de conhecimentos para resolução de problemas ao uso de recursos tecnológicos aplicados à Educação, possibilitando o desenvolvimento da observação, da investigação, do registro, da discussão e da sistematização e aplicação coletiva dos conhecimentos produzidos; focados no Minicurso por meio das oportunidades de interação coletiva via Fórum e nas situações de aprendizagem via ferramentas de produção coletiva, como a Wiki, contribuindo para a construção final de um projeto de extensão tecnológica em TS aplicável ao campus de atuação docente dos participantes.

Ao longo da pesquisa, os resultados e versões iniciais do conteúdo do produto foram apresentados a docentes e Técnicos do Instituto Federal de Sergipe - Campus Aracaju e debatidos durante jornada pedagógica centrada em propostas de viabilização do currículo integrado em EPT no IFS, gerando interessantes contribuições para a estruturação final do minicurso.

O minicurso, em versão finalizada, foi aplicado - após teste piloto - a um grupo de docentes e técnicos educacionais interessados do Instituto Federal de Sergipe - Campus Lagarto (unidade-caso), que avaliaram o produto por meio de pesquisa qualiquantitativa. Como resultados relevantes da fase quantitativa, $87,5 \%$ dos participantes avaliou positivamente tanto a viabilidade de compartilhar com os discentes o que foi construído ao longo do minicurso, como a aplicabilidade prática das aprendizagens e a viabilidade de implementar um projeto de extensão de TS com base no produto em seus campi. Na fase qualitativa, surgiram sugestões de aprimoramento da navegabilidade no minicurso e da usabilidade das ferramentas disponíveis na plataforma Moodle.

\section{CONSIDERAÇÕES FINAIS}

As suposições iniciais, que ajudaram a delinear o escopo da pesquisa geradora deste trabalho, sobre a natureza dos projetos de intervenção social em instituições federais e a falta de publicações de orientação metodológica para desenvolvimento de TS, foram corroboradas pelos levantamentos preliminares da pesquisa, apontando ser relevante a busca de informações sobre quais metodologias ou conjuntos sistemáticos de ações, etapas e procedimentos estão sendo utilizados para desenvolver, aplicar e reaplicar em projetos de TS no Brasil, que pudessem subsidiar a produção de um produto educacional de formação docente em TS.

Durante o delineamento metodológico da pesquisa, levantou-se a hipótese de que seria possível encontrar informações metodológicas para o desenvolvimento de TS no Brasil. Isso poderia ser feito por meio de um MSL dos artigos que abordassem projetos de TS implementados no Brasil recentemente e indicassem claramente suas etapas e procedimentos de desenvolvimento no sentido de gerar categorias temáticas analisáveis qualitativamente por um estudo de AT, gerando subsídios para o desenvolvimento de um produto educacional de formação docente em TS, o que, ao longo da pesquisa, mostrou-se uma opção efetivamente viável.. 
Apesar da quantidade relativamente pequena de artigos selecionados no MSL em relação ao universo inicialmente retornado, os resultados puderam esclarecer, além de outros aspectos, as bases metodológicas aplicadas aos projetos de TS mapeados, fornecendo dados importantes como a predominância do uso de "Metodologias próprias" de desenvolvimento de TS, construídas pelos próprios atores sociais envolvidos e segundo as especificidades de cada projeto.

Os resultados do MSL possibilitam a AT que se seguiu, quando foram analisadas qualitativamente as informações sobre processos e/ou fases aplicadas a cada tipo predominante de metodologia, com ênfase no que se conceituou e nomeou durante a pesquisa e neste trabalho de "Metodologias próprias".

Os resultados da AT subsidiaram de modo bastante satisfatório a sistematização de várias "Trilhas de desenvolvimento de TS" (estratégia criada e nomeada durante a pesquisa) baseadas nos achados qualitativos sobre os vários percursos de produção e aplicação de TS analisados. Tais trilhas indicam claramente as etapas, processos e instrumentos usados nas chamadas "Metodologias próprias", abordadas nos artigos analisados, e, somadas aos resultados obtidos nas etapas anteriores da pesquisa, compuseram o cerne do produto educacional, cumprindo os objetivos de pesquisa delineados no início deste trabalho, subsidiando satisfatoriamente um produto educacional de apoio ao trabalho docente voltado para a realização de projetos de extensão de desenvolvimento de TS para atender às necessidades das comunidades do entorno do IFS e contribuir para a formação integral e integrada de seus discentes.

Considera-se que o Minicurso de Formação em Tecnologias Sociais baseado nos resultados da pesquisa alcançou evidências positivas para se efetivar como primeiro passo na promoção do engajamento de docentes e técnicos em práticas de desenvolvimento de Tecnologias Sociais de modo sistematizado em seus campi, gerando soluções sustentáveis para os problemas relevantes para as comunidades locais e contribuindo para a formação integrada dos discentes; apoiando-os na construção, junto com seus alunos, de um intercâmbio efetivo de saberes e práticas com as comunidades locais, no sentido de favorecer a inclusão social de modo adequado em cada comunidade.

\section{REFERÊNCIAS}

ALBAGLI, Sarita.; MACIEL Maria. Lucia. Informação e conhecimento na inovação e no desenvolvimento local. Ci. Inf., Brasília, v. 33, n. 3, p.9-16, set./dez. 2004.

AULER, Décio.; SANTOS, Wildson Luiz Pereira dos. CTS e educação científica: desafios, tendências e resultados de pesquisa. Brasília, Editora Universidade de Brasília, 2011.

BAUMGARTEN, Maíra. (org.). TS e Inovação Social. In: Conhecimentos e redes - sociedade, política e inovação. Porto Alegre: Ed. Universidade/UFRGS, 2005.

BAUMGARTEN, Maíra. Tecnologias sociais, inovação e desenvolvimento. In: UNIRIO VII ESOCITE - Jornadas Latino-Americanas de Estudos Sociais das Ciências e da Tecnologia , Rio de Janeiro, 2008. p. 5 .

BRASIL, DECRETO Nº 6.095, DE 24 DE ABRIL DE 2007. Diretrizes para o processo de integração de instituições federais de educação tecnológica, para fins de constituição dos IFs de Educação, Ciência e Tecnologia - IFET. Brasília, DF, abr. 2007.

BRASIL, LEI No 11.892 DE 29 DE DEZEMBRO DE 2008. Instituição da Rede Federal de Educação Profissional, Científica e Tecnológica e criação os IFs de Educação, Ciência e Tecnologia. Brasília, DF, dez. 2008. 
BRAUN, Virginia.; CLARKE Victoria, V. Using thematic analysis in psychology. Qualitative Research in Psychology, Taylor \& Francis, London, 3 (2), p. 77-101, 2006.

CHEVALÉRIAS, François. (org). Enseigner les sciences à 1' école - cycles 1, 2 et 3. Edith Saltiel La main à la pâte; Université Paris 7, Centre national de documentation pédagogique. 2002.

CIAVATTA, Maria. RAMOS, Marise. Ensino Médio e Educação Profissional no Brasil - Dualidade e fragmentação. Revista Retratos da Escola, Brasília, v. 5, n. 8, p. 27-41, jan./jun. 2011.

CONSELHO NACIONAL DAS INSTITUIÇÕES FEDERAIS DE EDUCAÇÃO PROFISSIONAL E TECNOLÓGICA - CONIF. Extensão Tecnológica - RFEPCT, Cuiabá, 2013.

COSTA, Adriano. Borges. (org.). Tecnologia social e políticas públicas. Brasília: Fundação Banco do Brasil, 2013

DAGNINO, Renato; BRANDÃO, Flávio Cruvinel; NOVAES, Henrique Tahan. Contribuições ao marco analítico-conceitual da Tecnologia Social. In: DAGNINO, R. Tecnologia Social: ferramenta para construir outra sociedade. Campinas: Editora da Unicamp, 2004.

DAGNINO, Renato; BAGATTOLLI, Carolina. É possível transformar a Tecnologia Social em Política Pública? XXVII CONGRESO DE LA ASOCIACIÓN LATINOAMERICANA DE SOCIOLOGÍA. VIII Jornadas de Sociología de la Universidad de Buenos Aires. Asociación Latinoamericana de Sociología, Buenos Aires, 2009, p. 3-9.

DAGNINO, Renato (org). Tecnologia social: ferramenta para construir outra sociedade. 2. ed. rev. e ampl. Campinas: Komedi, 2010.

DAGNINO, Renato. Tecnologias Sociais: contribuições conceituais e metodológicas [online]. Campina Grande: EDUEPB, 2014.

DIAS JR, Jorge et al. Estudo empírico sobre adoção de SOA: um Mapeamento Sistemático da Literatura. Simpósio Brasileiro de Qualidade de Software, Salvador, 2013.

FEENBERG, Andrew. Teoria Crítica da tecnologia. Texto original "Critical theory of technology". Tradução da Equipe de Tradutores do Colóquio Internacional "Teoria Crítica e Educação". Piracicaba: Unimep, 2004.

FERRETI, Celso João et al. Novas Tecnologias, Trabalho e Educação: Um debate multidisciplinar. In: Cadernos de Pesquisa/Fundação Carlos Chagas, nº8, p. 90-94, maio 1994.

FRIGOTTO, Gaudêncio; CIAVATTA, Maria; RAMOS, Marise. (org.) Ensino Médio integrado: concepção e contradições. São Paulo: Editora Cortez, 2005.

FUNDAÇÃO BANCO DO BRASIL. Banco de Tecnologias Sociais. Disponível em: http:/ tecnologiasocial.fbb.org.br/tecnologiasocial/principal.htm. Acesso em: 10 jan. 2021.

GARCIA, J. C. D. Uma Metodologia de Análise das TS: as TS. Trabalho apresentado no XII Seminário Latino-Ibero-americano de Gestión Tecnológica - ALTEC 2007. Buenos Aires, set. 2007.

GARCIA, Pedro Benjamin. Educação Popular: Algumas reflexões em torno da questão do saber. In: BRANDÃO, Carlos Rodrigues (Org.) A questão política da Educação Popular. São Paulo, Brasiliense, 1980, p. 90 a 112.

GAPINSKI, Ecinoely Francine Przybycz; FREITAS, Carlos Cesar Garcia. Tecnologia social e órgãos públicos municipais: realidades e potencialidades. Revista Tecnol. Soc., Curitiba, v. 12, n. 25, p. 19-37, maio/ago. 2016. 
GODINHO, Manuel. Mira. Inovação e Difusão da Inovação: Conceitos e Perspectivas Fundamentais. In: RODRIGUES, Maria João et al (Org.). Para uma Política de Inovação em Portugal. Lisboa: D. Quixote, 2003. p. 27-51

ITS. Instituto de Tecnologia Social. Tecnologia Social no Brasil: direito à ciência e ciência para cidadania. Caderno de Debate. São Paulo: ITS, 2004.

JEZINE, Edineide. As Práticas Curriculares e a Extensão Universitária. Congresso Brasileiro de Extensão Universitária. 2 ed. Anais. Belo Horizonte, set. 2004.

JESUS, Vanessa. M. Brito; COSTA, Adriano Borges. Tecnologia Social: breve referencial teórico e experiências ilustrativas. In: COSTA, Adriano Borges (org.). Tecnologia Social e Políticas Públicas. São Paulo: Instituto Pólis, Brasília: Fundação Banco do Brasil, 2013, p. 17-32.

KLOSSOWSKI, Andressa; FREITAS, Carlos Cesar Garcia; FREITAS, Flaviane Pelloso Molina. O envolvimento da universidade pública em relação à tecnologia social. Revista Tecnologia e Sociedade. v. 12, n. 26, p. 62-76, 2016.

KUENZER, Acácia Zeneida. Educação Profissional: categorias para uma nova pedagogia do trabalho. Boletim Técnico do Senac, Rio de Janeiro, v. 25, n. 2, maio/ago. 1999.

LATOUR, Bruno. Jamais fomos modernos: ensaio de antropologia simétrica. Rio de Janeiro: Editora 34, 1994.

LUNDVALL, Bengt-Âke. Innovation, growth and social cohesion: the Danish model. Cheltenham: Edward Elgar Publishing, 2002.

MACHADO, Lucília Regina de Souza. Diferenciais inovadores na formação de professores para a educação profissional. Revista Brasileira da Educação Profissional e Tecnológica, Brasília, v. 1, n. 1, p. 8-22, 2008.

MACIEL, Ana Lúcia Suárez.; FERNANDES, Rosa Maria Castilhos. Tecnologias sociais: interface com as políticas públicas e o Serviço Social. Serviço Soccial \& Sociedade [online]. 2011, n.105, pp.146-165.

MONIZ, Marcela de Abreu et al Diagnóstico participativo socioambiental e de riscos à saúde das comunidades do entorno do Complexo Petroquímico do Rio de Janeiro, Brasil. Ciênc. saúde coletiva [online], vol.22, n.11, p.3793-3806, 2017.

MOURA, Dante Henrique. Trabalho e formação docente na educação profissional. Curitiba: Instituto Federal do Paraná, 2014. (Coleção Formação pedagógica, v. 3). Disponível em: https://curitiba.ifpr.edu.br/wp-content/uploads/2016/05/Trabalho-e-Forma\%C3\%A7\%C3\%A3oDocente.pdf. Acesso em: 10 jan. 2021.

MULGAN, Geoff. The process of social innovation. Innovations: technology, governance, globalization. Cambridge: MIT Press, p. 145 - 162, Spring, 2006.

OLIVEIRA, Edson Marques. Tecnologia social, universidade e sociedade: a extensão como espaço estratégico de intervenção. Revista Tecnologia e Sociedade, v. 9, n. 17, p. 51-63, 2013.

PATRUCCO, Pier Paolo. Institutional variety, networking and knowledge exchange: communication and innovation in the case of the Brianza technological district. Regional Studies, v. 37, n. 14, p. 159-172, Apr. 2003.

PETERSEN, Kai et al. Systematic Mapping Studies in Software Engineering. In: PROCEEDINGS OF THE 12TH INTERNATIONAL CONFERENCE ON EVALUATION AND ASSESSMENT IN SOFTWARE ENGINEERING. Anais EASE'08. Swindon, UK: BCS Learning \& Development Ltd., 2008. 
PICHETTI, Roni Francisco. Tecnologia social nos núcleos de inovação tecnológica dos institutos federais de educação, ciência e tecnologia brasileiros. Dissertação de Mestrado. Fundação universidade Regional de Blumenau Centro de Ciências Humanas e da Comunicação - Programa de Pós-Graduação em Desenvolvimento Regional. Blumenau, 2018.

PINTO, Álvaro Vieira. O conceito de tecnologia. Rio de Janeiro: Contraponto, 2005.

RODRIGUES, Ivete; BARBIERI, José Carlos. A emergência da TS: revisitando o movimento da tecnologia apropriada como estratégia de desenvolvimento sustentável. Rev. Adm. Pública, v. 42, n. 6, p. 1069-94, nov./dez. 2008.

ROLLEMBERG, Graziella.; FARIAS, Mário de Freitas. Tecnologias sociais, formação docente e comunidades de aprendizagem: um desafio contemporâneo. In: VII WORKSHOP DE DESAFIOS DA COMPUTAÇÃO APLICADA À EDUCAÇÃO. Anais Sociedade Brasileira de Computação (SBC), Porto Alegre, 2018.

ROSA, Valdir. et al. Hands-on-tec: Estratégia pedagógica e tecnologias móveis. In: Challenges 2013: Aprender a qualquer hora e em qualquer lugar, learning anytime anywhere. Braga: Centro de Competência TIC do Instituto de Educação da Universidade do Minho, v.1, p. 581-592, 2013.

SANT’ANNA, Vanya Mundin. Ciência e Sociedade no Brasil. São Paulo: Símbolo, 1978.

SOFFNER, Renato Kraide. Tecnologias Sociais e a educação para a práxis sócio comunitária. SérieEstudos -Periódico do Programa de Pós-Graduação em Educação da UCDB Campo Grande, MS, n. 37, p. 309-319, jan./jun. 2014

SOUZA, Denner Santiago de; RUFINO, Sandra. Tecnologias sociais: panorama da Universidade Federal do Rio Grande do Norte. R. Tecnol. Soc. Curitiba, v. 13, n. 29, p. 104-115, set./dez. 2017.

TENNANT, Mark C., POGSON, Phillip. Learning and Change in the Adult Years: A Developmental Perspective. San Fancisco: Jossey-Bass, 1995.

ZEICHNER, Kenneth. M. Uma análise crítica sobre a "reflexão" como conceito estruturante na formação docente. Educ. Soc., Campinas, vol. 29, n. 103, p. 535-554, maio/ago. 2008.

Submetido: $13 / 01 / 2020$

Aprovado: 07/01/2021 